\title{
Thinking Through Dilemmas
}

Departing from the sociological dual process model that divides thoughts into automatic and unconscious, or deliberate and conscious occurrences, this book draws on empirical cases to demonstrate the existence of "automatic deliberation." Through research into the ways in which people address difficult subjects, such as death and dying, pedophilia, and career decision-making, the author sheds light on a mode of thinking which is both habitual and effortful, displaying a combination of habituated understandings and conscious deliberation. Advancing a blended view of cognition by which individuals draw on schemas and frames to think through complex topics, this volume will appeal to sociologists and psychologists with interests in cognition and the ways in which we make decisions.

Lawrence H. Williams is visiting assistant professor in the Department of Sociology at the University of Toronto, Canada. 


\section{Routledge Advances in Sociology}

282 The Global Citizenship Nexus

Critical Studies

Edited by Debra D. Chapman, Tania Ruiz-Chapman and Peter Eglin

283 People, Care and Work in the Home

Edited by Mohamed Gamal Abdelmonem and Antonio Argandona

284 Europe In Love

Binational Couples and Cosmopolitan Society

Juan Díez Medrano

285 Neurodiversity Studies

A New Critical Paradigm

Edited by Hanna Bertilsdotter Rosqvist, Nick Chown

and Anna Stenning

286 The Class Structure of Capitalist Societies

Volume 1: A Space of Bounded Variety

Will Atkinson

287 Studies on the Social Construction of Identity and Authenticity

Edited by J. Patrick Williams and Kaylan C. Schwarz

288 Globalisation, Tourism and Simulacra

A Baudrillardian Study of Tourist Space in Thailand

Kunphatu Sakwit

\section{Thinking Through Dilemmas}

Schemas, Frames, and Difficult Decisions

Lawrence $H$. Williams

For more information about this series, please visit: www.routledge.com/ Routledge-Advances-in-Sociology/book-series/SE0511 


\title{
Thinking Through Dilemmas Schemas, Frames, and Difficult Decisions
}

\section{Lawrence H. Williams}

\author{
를 Routledge \\ 量 Taylor \& Francis Group \\ LONDON AND NEW YORK
}


First published 2021

by Routledge

2 Park Square, Milton Park, Abingdon, Oxon OX14 4RN

and by Routledge

52 Vanderbilt Avenue, New York, NY 10017

Routledge is an imprint of the Taylor \& Francis Group, an informa business

(C) 2021 Lawrence H. Williams

The right of Lawrence $\mathrm{H}$. Williams to be identified as author of this work has been asserted by him in accordance with sections 77 and 78 of the Copyright, Designs and Patents Act 1988.

All rights reserved. No part of this book may be reprinted or reproduced or utilised in any form or by any electronic, mechanical, or other means, now known or hereafter invented, including photocopying and recording, or in any information storage or retrieval system, without permission in writing from the publishers.

Trademark notice: Product or corporate names may be trademarks or registered trademarks, and are used only for identification and explanation without intent to infringe.

British Library Cataloguing-in-Publication Data

A catalogue record for this book is available from the British Library

Library of Congress Cataloging-in-Publication Data

Names: Williams, Lawrence H., 1987- author.

Title: Thinking through dilemmas : schemas, frames, and difficult decisions / Lawrence H. Williams.

Description: Abingdon, Oxon ; New York, NY, : Routledge, 2020. | Series: Routledge advances in sociology | Includes bibliographical references and index.

Identifiers: LCCN 2020015757 (print) | LCCN 2020015758 (ebook) |

ISBN 9780367511630 (hardback) | ISBN 9781003052654 (ebook)

Subjects: LCSH: Dilemma. | Decision making. | Thought and

thinking.

Classification: LCC BC185 .W555 2020 (print) | LCC BC185 (ebook) |

DDC 302.3- dc23

LC record available at https://lccn.loc.gov/2020015757

LC ebook record available at https://lccn.loc.gov/2020015758

ISBN: 978-0-367-51163-0 (hbk)

ISBN: 978-1-003-05265-4 (ebk)

Typeset in Times New Roman

by codeMantra 


\section{Contents}

List of figures vii

1 Introduction 1

2 The patterned spontaneity of reasoning 28

3 The reflective management of desire 67

4 The automatic yet iterative use of schemas 97

5 Conclusion 134

$\begin{array}{ll}\text { Index } & 147\end{array}$ 

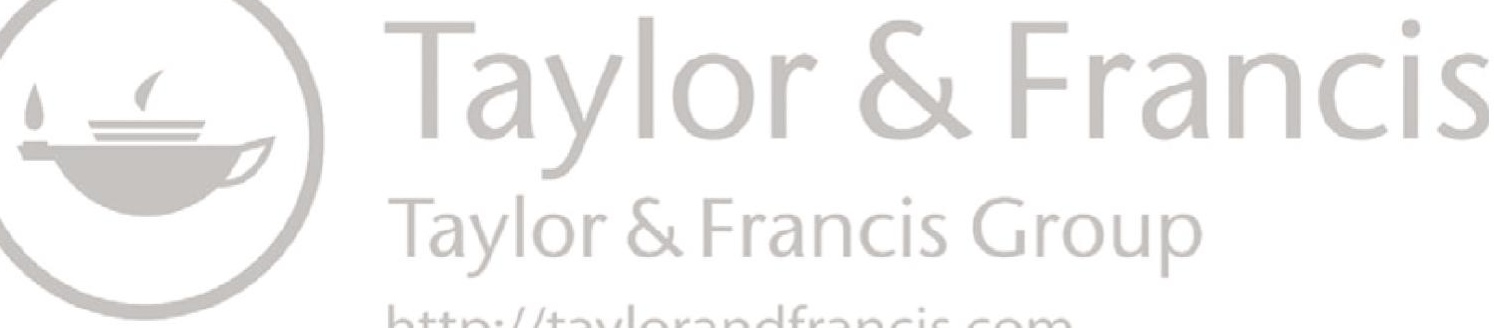

http://taylorandfrancis.com 


\section{Figures}

2.1 Consultation to comfort and well-being to value. This pinball machine represents the most common trajectory (61.5\% of interviewees): Consultation $\rightarrow$ Comfort and WellBeing $\rightarrow$ The Value of Life. The dashed line represents the individual's movement through these three phases, with the direction of the line indicating the time spent in each phase. In this trajectory, individuals tended to quickly move to issues of comfort and well-being, stay in this phase for a significant amount of time as they bounced between ideas of pain and quality of life, and then gradually work their way into broader, existential issues such as the intimate nature of end-of-life decisions

2.2 Consultation to value. This pinball machine represents the second most common trajectory ( $23 \%$ of interviewees): Consultation $\rightarrow$ The Value of Life. Interviewees captured in this figure tended to very quickly jump to Phase 3 , moving from an immediate affirmation or rejection of the question of Frank's consultation justified by existential concerns such as his potential outlook on the value of life. The zig-zagging of the dashed line in Phase 3 captures the fact that interviewees typically bounced between different ideas within the broader schema of the Value of Life, such as religious perspectives, hope, and personal philosophies, based on how these ideas either resonated with them personally or were imagined to possibly resonate with Frank

2.3 Consultation to value to comfort and well-being to value. This pinball machine represents the third most common trajectory (15.5\% of interviewees): Consultation $\rightarrow$ The Value of Life $\rightarrow$ Comfort and Well-being $\rightarrow$ Value $(15.5 \%)$. Interviewees characterized by this trajectory tended to be more circuitous in their responses, generally, marked by longer durations in each phase. This more circuitous path was largely the consequence of these interviewees more 
effortfully deliberating about Frank's consultation, then further thinking through this issue in an existential sense using ideas of personal values (Phase 3 ), then drawing on experiences of loved ones who fell ill and may have made these sorts of decisions (Phase 2), and then ultimately back to considering this topic as dilemmatic due to its subjective nature (Phase 3)

3.1 The nature frame $\quad 79$

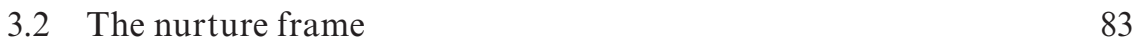

$\begin{array}{ll}3.3 & \text { The culture frame } \\ 3.4 & 86\end{array}$

3.4 The complete framing model 88

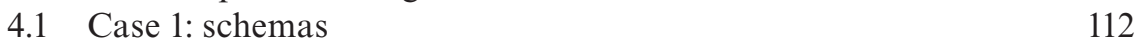

4.2 Unmet expectations. Career experiences which lead to the experience of unmet expectations tended to lead to career change, with career change leading to a positive career outlook for interviewees. However, when either of the responsibility schemas was utilized, career continuity became increased, leading to increased chances of these individuals feeling negative or neutral toward the futures of their careers

4.3 Met expectations. Career experiences which lead to the experience of having met their career expectations tended to lead to career continuity, with staying in the same career leading to a positive career outlook for interviewees. However, when either of the responsibility schemas was utilized, individuals became increasingly likely to change their careers, leading to increased chances of these individuals feeling negative or neutral toward the futures of their careers as they became increasingly reflective about their career decisions which often led to indecisiveness about what to do next

4.4 The full career model. This model depicts how expectations shape future career paths based on the extent to which they lead to the use of schemas about personal failure and societal responsibility 


\section{Introduction}

\section{Introduction}

Sociologists have long been interested in how individuals make decisions. These efforts can be seen in the long and checkered history of Parsons' (1949) infamous theory of action. His theory of action was an attempt to unite hitherto disparate accounts of how and why individuals make the decisions that they do and, more broadly, come to think and act as they do (see Gerhardt 2011). Many sociologists increasingly came to see Parsons' account as overly value-driven and deterministic, however, and the discipline began to splinter between accounts which emphasize the relatively automatic, tacit, and habitual on the one hand - such as everyday habits of dress and work and those which emphasize the more effortful, conscious, and deliberate on the other hand - such as engaging in a verbal argument, solving a complicated math equation, or reflecting on a topic (see Cerulo 2018; Leschziner 2019; Patterson 2014; Vaisey 2009). In short, sociologists moved away from a view of normatively determined action toward perspectives which assume either that the bulk of our behavior is habitual and unconscious or that it is deliberate and conscious (see Patterson 2014). ${ }^{1}$

Moreover, the cognizance that individuals think and act using either habit or deliberation in any given moment has led to a growing debate among sociologists regarding the role that each of these factors plays in any actual decision or action an individual makes (see Cerulo 2018; DiMaggio 1997; Leschziner 2019; Mische 2014; Moore 2017; Patterson 2014; Vila-Henninger 2015). Scholars tend to emphasize either habitual thought and action as influenced by internalized values and mental representations or schemas (e.g., Bourgois and Schonberg 2009; Martin and Desmond 2010; Miles 2014; Vaisey 2009), or to emphasize effortful deliberation as influenced by reflexivity, situational constraint, and context (e.g., Archer 2007; Swidler 1986, 2001). While proponents of both views share the same underlying assumptions about thought and action - namely, that thought and action can be conceived of as the interplay between (a) internalized mental structures that individuals accumulate throughout their lives which enable the perception of their surroundings (Mead 1934) and (b) growing self-concepts 


\section{Introduction}

that, while informed by individuals' experiences, are not fully reducible to them (Leschziner 2015; Winchester and Green 2019) - they differ in regard to which of these factors they emphasize in their explanations (see Lizardo and Strand 2010).

This division between the habitual and effortful qualities of thought and action can be seen most saliently in the recent widespread use of the sociological dual process model (SDPM) (see Cerulo 2018; DiMaggio 1997; Lizardo and Strand 2010; Vaisey 2009; Vila-Henninger 2015). According to the SDPM, individuals think and act automatically and unconsciously, or deliberately and consciously (Leschziner 2019; Lizardo et al. 2016). The core of this model is based on psychological dual process models, which assume that cognitions occur either unconsciously and automatically, relying on what are called Type 1 processes, or consciously and deliberately, relying on what are called Type 2 processes (Evans 2010; Vaisey 2009). ${ }^{2}$ The SDPM arguably gained traction in sociology after Vaisey (2009) leveled criticism against many sociologists for privileging situational aspects of individual action over more dispositional and ingrained elements (see Leschziner 2019; Vaisey 2009; Winchester and Green 2019). ${ }^{3}$ Vaisey (2009) argued that interview methods typically only allow access to individuals' post hoc justifications of why they think and act as they do, and instead advocated for the examination of more deep-seated drivers of motivation. This involved longitudinal survey research which could examine how responses to questions at one point in time could indicate the presence of dispositions or worldviews which were predictive of individuals' future behavior (see Winchester and Green 2019).

However, a recent but robust line of sociological work has challenged the SDPM in regard to its assumptions that Type 1 and Type 2 processes are sharply divided and that Type 2 processes typically are engaged when Type 1 processes fail to enable individuals to solve problems (e.g., Cerulo 2018; Leschziner 2015; Leschziner and Green 2013; McDonnell 2014; Winchester 2016; Winchester and Green 2019). This view of SDPM placing too much emphasis on the division between Type 1 and Type 2 cognition is shared by sociologists studying topics ranging from chefs (Leschziner 2015), to AIDS campaigns (McDonnell 2014), to religious belief (Winchester 2016). Common among scholars in this camp - and indeed, in what appears to be a growing reaction to much of the use of the SDPM - is the belief that the distinction between Type 1 and Type 2 processes often blurs as individuals muddle their way through situations in ways which appear to be shaped by both routine and effortful processing, such as instances where an individual relies on tried-and-true methods for solving novel math equations (De Neys 2018), develops new culinary dishes when tasked to be innovative (Leschziner 2015), or deciphers and explains responses to scents and fragrances (Cerulo 2018).

In this book, I follow this camp of scholars by showing how the SDPM's assumptions about the discrete nature of automatic or Type 1 and 
deliberate or Type 2 processing do not account for moments of cognition which demonstrate what I term automatic deliberation: a kind of processing which is cognitively costly (effortful) but which is also rapid, often occurs over long spans of time and tends to occur seemingly unprompted (see De Neys 2018). I support my argument by integrating Vila-Henninger's (2015) claim that motivations may at times be conceptualized as Type 2 with recent theorizing on the concepts of resonance (McDonnell et al. 2017) and accounts (Winchester and Green 2019). Together, this work enables me to conceptualize moments of deliberation which occur rapidly and without explicit prompting as demonstrating a blend of Type 1 and Type 2 processing, and as being the product of how schemas and frames - embodied and internalized mental representations which enable rapid and automatic perception of similar stimuli, and publicly available discursive understandings and/or material objects, respectively (see Kinder and Sanders 1990; Wood et al. 2018) - resonate with individuals when discussing a variety of topics.

Frames tend to drive social relations, as they serve as the foundations for social organization and classification, while schemas often are the tacit residues of these frames. Frames are publicly available, discursive understandings, while schemas are the internalized, mentally stored residues of these understandings (see Kinder and Sanders 1990; Wood et al. 2018). For example, gender operates as a "primary frame" in North American society by being a key marker of difference and social sorting (Ridgeway 2009). Living in a society with such a frame thus leads individuals to develop "gender schemas" based on their repeated exposure to a gender-based social organization (Bem 1981). Thus, throughout this book, frames will refer to the declarative culture that individuals can learn, talk, and think about, while schemas will refer to these cultural products' internalized residues or the mental representations that they cause individuals to develop and, in turn, automatically use to navigate their worlds. ${ }^{4}$ Resonance is the experience of a message, discourse, or other cultural object fitting with an individual's current worldview (McDonnell et al. 2017). This feeling of "fit" or resonance shapes the extent to which schemas or frames lead individuals to act or reflect in the effort to solve a problem (see McDonnell et al. 2017). For example, schemas about the importance of comfort and well-being tend to cause individuals to refine their claims about resuscitation and the end of life; frames around the developed and socially constructed nature of pedophilia often lead individuals to either seek therapy or "condemn the condemners" (Sykes and Matza 1957:668) by renouncing the reality of their sexual dysfunction; and schemas around personal responsibility and societal responsibility lead individuals to alternate between viewing their career experiences as part of a purposive path or as the product of largely unmet expectations.

Moreover, by mapping out the reasoning paths of individuals across my three cases, I demonstrate how non-declarative, embodied schemas give way to declarative, discursive frames as individuals attempt to work through topics that they find problematic. For individuals who perceive 
their respective topic as fundamentally dilemmatic, schemas are more likely to give way to frames, and frames are more likely to be desired to become schemas - individuals in dilemmatic situations are more likely to explain in detail the logic behind their largely Type 1-based beliefs and understandings, but are also more likely to speak or write with passion, anger, sadness, and other markers of emotional intensity when moving from framing topics generally to applying them to concrete situations in their attempts to resolve topics they view as problematic (see McDonnell et al. 2017). In turn, I demonstrate how individuals automatically deliberate by moving from schemas to frames, from frames to schemas, and in cycles between these two forms of culture in their broader attempts to solve the problems they are thinking through (see Cerulo 2018; Lizardo 2017; McDonnell et al. 2017; Wood et al. 2018).

Moreover, I demonstrate how the study of dilemmatic topics offers special insight into this process due to the emotionally laden and prolonged nature of individuals' thoughts about these topics (see Ramvi et al. 2018; Van der Kolk 2014). Dilemmas can be differentiated from problems due to their protracted, enduring, and ambivalent nature; they may appear to be solved but then resurface, or they may appear to individuals as ongoing problems that cannot be solved at all (Ramvi et al. 2018). Indeed, common among many of the self-narrations presented in each set of data is the experience of great stress caused by the ambivalence involved in each case - enduring memories of the death and dying of loved ones bring about positive memories but also memories of unfortunate circumstances and failed attempts to prolong life; unrequited love and sexual desires spark both passion and disgust when the objects of these desires are minors; and careers and career decisions bring about memories of meaningful work but also of failed opportunities, bad bosses, and the elusive nature of vocations. Analyzing these narrations as vehicles through individuals attempt to think through deep-seated, embodied emotions (see Janet 1904; Van der Kolk 2014; Van der Kolk and Fisler 1995; Van der Kolk and Van der Hart 1991; Wood et al. 2018) will therefore contribute to current sociological theorizing on the differences in the use of declarative frames (those narrations somewhat distant from a person) and non-declarative schemas (those narrations which appear to be based on tacit understandings) (see Wood et al. 2018).

Following the lead of sociologists who view the use of schemas and frames as fundamentally interactional and problem-oriented (e.g., Leschziner 2015, 2019; McDonnell 2014; McDonnell et al. 2017; see also Winchester and Green 2019; Wood et al. 2018), I demonstrate the act of automatic deliberation using the empirical cases of death and dying, pedophilia, and career decision-making. In each case study, I was able to discern how individuals approached their respective topics in light of broader understandings and experiences but in patterned ways based on the schemas and frames they tended to use, and map out how these understandings and experiences informed the reasoning processes that these individuals engaged in. I was 
further able to discern the extent to which this process involved Type 1 or Type 2 processing by analyzing how schemas and frames resonated with and were alternated between by individuals in these cases, focusing on the extent to which these heuristics resonated with their various experiences as observed through the presence of focused deliberation and/or emotional intensity (see McDonnell 2014; McDonnell et al. 2017). For death and dying, this involved seeing answers about life prolongation as shaped by individuals' prior experiences with sick loved ones, as well as information about the experiences of others, leading interviewees to tend to automatically deliberate about end-of-life decisions largely by utilizing routinely used schemas about life and death. For pedophilia, this involved seeing claims about their sexuality as grounded in previous frustrations, negative emotions, and a context of censure and taboo, ultimately leading individuals to tend to automatically yet effortfully analyze this sexual disorder (see Goode 2010) as they discussed different frames of pedophilia. Lastly, for career decision-making, this involved interpreting answers to the questions I posed my interviewees as being shaped by previous work experiences, prior expectations about the work they engaged in, and current plans for moving forward with their careers as narrated through the lens of schemas about the nature of work which varied in resonance based on the salience of these individuals' career expectations.

As will be shown, my finding that individuals automatically cycled through schemas and frames about these topics signals that the SDPM should be refined through the incorporation of recent research which has demonstrated the blended nature of automatic and deliberate processes in individuals' everyday thoughts and actions (see Cerulo 2018; Evans and Stanovich 2013; Lamont and Swidler 2014; Leschziner 2015; Leschziner and Green 2013; Pugh 2013; Schwarz 2015; Vila-Henninger 2015; Winchester 2016). ${ }^{5}$ Doing so will showcase how individuals automatically deliberate in three different empirical domains and, as such, provide a theoretical framework for future research in areas where individuals are often particularly uncertain about the decisions that they make (see Winchester and Green 2019). Moreover, it can further contribute to how individuals use schemas and frames by extending McDonnell et al.'s (2017) claims about the individual nature of frames' resonance with that of Wood et al.'s (2018) claims about the inherently resonant nature of schemas. While McDonnell et al. (2017:5) claim that frames resonate with individuals precisely because of the "cognitive distance" individuals have from them - such as the emotional power that metaphors have, like Shakespeare's "Juliet is the sun" - schemas resonate because they work to solve problems automatically and at an unconscious level. This is why statements such as "Juliet is a girl" do not resonate - because this association is so wholly aligned, no cognitive distance is achieved and, thus, despite being a strong connection, sparks little to no emotion in individuals other than, perhaps, boredom (McDonnell et al. 2017). Thus, by demonstrating how schemas are used to solve routine problems, while frames are used to 


\section{Introduction}

attempt to solve novel or persistently unsolvable problems by enabling individuals to metaphorically reframe their schematic interpretations, I combine insights about resonance with those of dual process theorizing to argue that automatic deliberation - that is, the alternation between schemas and frames to think through problems - requires examination of how, why, and to what extent schemas and frames differ in terms of how they are used by individuals to solve problems. ${ }^{6}$

To make sense of how schemas and frames can be automatically deployed despite their ontological differences (with the former being non-declarative and embodied, and the latter being declarative and discursive), I draw on two cognitive models which assume more blended views of automatic and deliberation processes - the parallel dual process model (PDPM) (Pennycook 2018) and the hybrid dual process model (HDPM) (De Neys 2018). The PDPM assumes that Type 1 and Type 2 processes occur rapidly in an iterative manner, ultimately framing these processes as parallel rather than sequential in that both processes are frequently used in quick succession to aid individual perception (Pennycook 2018). By contrast, the HDPM assumes that this iteration may itself be prompted by conflict between Type 1 heuristics, making the process of deliberation or Type 2 processing itself mostly automatic - hence the hybrid nature of the two types of processing assumed by this model (Bago and De Neys 2017, 2019). By focusing on topics which often require active deliberation based on the presence of multiple conflicting schemas and frames for thinking through these topics - such as pedophilia as a sexual orientation versus a sickness, and career worries as the result of personal or societal failures - I demonstrate how such acts of deliberation are shaped by automatic processes in ways which make accounts of either pure Type 1 or pure Type 2 thought and action rather unconvincing (see Leschziner 2019; Moore 2017; Vila-Henninger 2015). In relation to the PDPM, I demonstrate how individuals cycle between schemas and frames in rapid succession, and in relation to the HDPM, I demonstrate how this cycling often appears to be primarily Type 1 as individuals tend to rapidly cycle through declarative or Type 2 frames based on how they resonate with non-declarative or Type 1 schemas - frames such as the "pedophile monster" resonate with individuals based on schemas they have routinized around morality (see Vaisey 2009; Vaisey and Lizardo 2010); schemas about living a pain-free life become declarative, by contrast, when filtered through schemas regarding the importance of autonomy and freedom of choice; and schemas about personal fulfillment give rise to declared denouncements of the status quo when individuals consider how their careers have failed them at a personal, schematic level in terms of vocational expectations.

To demonstrate how and why schemas and frames resonate for individuals and shape the conclusions they arrive at, I map out the paths that individuals take as they reason through these dilemmatic topics and use the term cognitive path to describe this. Cognitive paths are the routes that individuals tend to take when reasoning through particular topics which can fruitfully 
be unpacked in terms of which ideas are called upon, how they are used, and how they take shape throughout an individual's overall response trajectory. Cognitive paths enable clear showcasing of not only which schemas and frames are used by individuals as they think through topics, but the extent to which these heuristics acquire resonance in this process - the pathways demonstrate how particular schemas and frames become amplified based on individuals' life histories, as such calling for the integration of research on schemas and frames with research on identity (see Winchester and Green 2019). Moreover, cognitive paths showcase how what makes particular topics dilemmatic for individuals is that they cannot reconcile the "cognitive distance" (McDonnell et al. 2017:5) between their declarative knowledge and their phenomenological experience; they either know (declarative) or feel (nondeclarative) that something has gone awry, but cannot pinpoint exactly what it is - individuals contemplating death and dying know that people vary in terms of attitudes toward life prolongation but feel particular ways about this based on their own experiences; non-active pedophiles tend to think that pedophilia is perverse but feel that they honestly did not choose this desire; and individuals with unmet career expectations know that their personal decisions may have played a part in their relative misfortunes but feel that their governments and communities should have helped prevent them from embarking on failed career paths.

Examining the relationship between schemas and frames as they pertain to problem-solving is also needed as researchers have tended to privilege the habitual aspects of thought and action (see Mische 2014; Moore 2017). Such a focus has led much of the research on more effortful thought and action to, therefore, focus on the solution of bounded problems (see McDonnell et al. 2017) - such as how individuals navigate complex spaces (e.g., Harvey 2010) or how they make educational decisions (e.g., Archer 2007). Many acts of deliberation span longer periods of time, however, as there is no single action that can resolve the problem in question (Hansson et al. 2003); these moments can be conceptualized as what McDonnell et al. (2017:10) call "resonance in motion": moving from the problem situation, to the feeling of resonance, to action and continuing, potentially, in an ongoing cycle. ${ }^{7}$ Examining resonance in motion is thus the focus of this book, with the specific topics of death and dying, pedophilia, and career decision-making all sharing in common the fact that not only are conflicting ideas present on these topics in contemporary society, but that individuals' attitudes about these topics often remain undetermined despite frequent declarations of resonance. Issues of end-of-life care and life prolongation are seldom settled easily (Seymour 2003), and the sorrow that comes along with acknowledgment of one's mortality itself gives rise to a wave of emotions cascading from fear to hope (Kübler-Ross 1969; Ramvi et al. 2018). Pedophiles are widely condemned yet increasingly shown tolerance due to the recent scientific debate regarding pedophilia as a sexual orientation (Goode 2010; Seto 2009, 2012), and careers are becoming more lateral and boundaryless 


\section{Introduction}

yet individuals often appear to want more stable, long-term employment (see Cowen 2017; Twenge 2017). As such, these cases were chosen as they represent areas of social life that confront individuals as ongoing dilemmas that they not only may have to think about but often have to struggle to think through. As will be shown, individuals in these three cases often think they have things figured out, but then come to reframe their schematized and habituated dispositions as problematic in light of new situations and new information; these factors become "ends-in-view" and part of a larger puzzle demanding a solution (see Dewey 1988:225; McDonnell et al. 2017; Whitford 2002). Examining how individuals demonstrate not only different amounts of deliberation in each of these areas but different styles of deliberation based on just how persistent or unresolvable these issues are for them is, therefore, a key focus of this book.

\section{The sociological dual process model and its discontents}

Scholars of cognition have been divided in their support for this version of the dual process model, what has been called the default-interventionist model (De Neys 2018; Evans 2012; Evans and Stanovich 2013) due to its assumption that Type 1 processing is the default mode of cognition, with Type 2 processing occurring only when the former processes do not enable an individual to maintain her behavior without conscious deliberation. While many scholars do - even if only implicitly - support the default-interventionist model (e.g., Haidt 2001, 2005; Martin and Desmond 2010; Miles 2014; Vaisey 2009), others - also implicitly - support what is known as the PDPM (see De Neys 2018), a model which asserts that Type 1 and Type 2 processes can work simultaneously (e.g., Danna-Lynch 2010; Harvey 2010; Leschziner and Green 2013; Mische 2014; Moore 2017). That is, according to proponents of the PDPM, cognition is framed as relying on both Type 1 and Type 2 processes either simultaneously or sequentially, but with the latter, in a more iterative, cyclical manner than is assumed in the default-interventionist model (see Betsch and Glöckner 2010; Ferreira et al. 2006; Sloman 2014; Thompson and Newman 2018; Trippas and Handley 2018). For example, when confronted with a stimulus, an individual may automatically draw on multiple appropriate heuristics (Pennycook 2018). This may then prompt the individual to have to consciously choose a heuristic through which to understand what is in front of her, though in the majority of cases this conflict does not occur (Pennycook 2018). ${ }^{8}$ In short, proponents of the PDPM assume that Type 1 and Type 2 processing are both simultaneously available to individuals in any situation, but that the use of either process depends on the extent to which individuals gauge a situation as requiring deliberate thought. As will be shown, however, this model itself has been challenged by proponents of the HDPM for still maintaining too strong of a division between Type 1 and Type 2 processing. 
This kind of dual processing has been implicitly supported by sociologists who emphasize the contextual nature of cognition and who find that individuals engage in automatic or deliberate cognition based on situational constraints (e.g., Harvey 2010; Leschziner and Green 2013; Shepherd 2011). For example, Harvey (2010:185) analyzed the ways in which physical space triggers either automatic or deliberate cognition in individuals, based on the complexity and familiarity of these spaces' structures. He found that spaces with more complicated structures (e.g., libraries with disorganized book shelving) trigger deliberate thinking in individuals, whereas simpler spaces (e.g., small convenience stores with ample signage and typical layouts) trigger automatic cognition in individuals (Harvey 2010:186). Similarly, DannaLynch (2010) argues that individuals can consciously or unconsciously switch into particular roles based on cues in their environments. As individuals switch between myriad roles on any given day (e.g., from a co-worker, to a father, to a husband), they must determine which role they should be playing in any particular situation they encounter. Danna-Lynch (2010:181) argues that individuals engage in what she terms "mental weighing" in order to do this. When individuals have the time to think about their role switches, they engage in deliberative thought in order to do so (Danna-Lynch 2010). When they do not have the time, they feel "pushed" into roles automatically (Danna-Lynch 2010). Key in both Harvey's (2010) and Danna-Lynch's (2010) use of dual processing is the idea that individuals' alternations between Type 1 and Type 2 processes are context-specific, as sometimes automatic cognition is primed through seamless recognition of an environment, whereas at other times more concentrated thinking is required to figure out how to proceed. As such, these sociologists support a model which, rather than privileging Type 1 over Type 2 processes, sees context as largely determining which of these takes precedence.

The idea that individuals alternate between Type 1 and Type 2 processes through either rapid iteration as posited by the PDPM or due to contextual reasons as posited by sociologists such as Harvey (2010) and Danna-Lynch (2010) does not account, however, for times when these two processes may overlap (see Cerulo 2018). While finding one's way through an area or role-switching may prompt a person into more Type 1- or Type 2-oriented thinking, many situations may call for a fusion of these processes. Indeed, De Neys (2018) argues that individuals often automatically alternate between Type 1 heuristics when confronted with novel or problematic situations, as they quickly change course based on automatically perceived logical inconsistencies presented to them. In turn, De Neys (2018) argues that this kind of automatic deliberation signals a much more blended nature of the two types than is assumed in both the default-interventionist and PDPMs: HDPM (see also Elqayam and Over 2012; Frankish 2012; Macchi and Bagassi 2012; Sun and Mathews 2012; Thompson and Newman 2018). Rather than assume that Type 1 and Type 2 processes are discrete and work either in isolation or in 
a cyclical manner, De Neys (2018) extends the notion of parallel processes to argue that the perception of conflict between heuristics when perceiving a stimulus need not be conscious or Type 2 at all. His work, therefore, also implicitly critiques the sociological context-based uses of the SDPM cited in the previous paragraph, as these efforts also share the relatively sharp division between Type 1 and Type 2 processes shared by the PDPM.

The HDPM is supported by experiments that were designed to gauge the extent to which engaging in deliberate, Type 2 thought would help interviewees correct responses that they gave to questions under time constraints which were assumed to elicit automatic, Type 1 cognitions (Bago and De Neys 2017, 2019). These studies challenge the SDPM's assumption that the use of deliberate thinking often occurs to correct or refine responses to questions given automatically by individuals. Indeed, Bago and De Neys $(2017,2019)$ found that participants tended to maintain their initial answer when deliberating ( $48 \%$ to $76 \%$ of responses). Moreover, this occurred when their initial responses were either correct or incorrect, indicating that many individuals actually engage in effortful thought to support and justify their responses rather than to augment or refine them (Bago and De Neys 2017, 2019). ${ }^{9}$

De Neys' (2018) claim about Type 1 conflict between heuristics lays the foundation for my book's central contributions: (a) the demonstration of the utility of the HDPM for sociological analysis of how individuals think through dilemmas; and (b) the demonstration of the blended nature of habit and effort in individuals' thought processes (see Cerulo 2018; Eliasoph and Lichterman 2003; Leschziner 2015; Lizardo and Strand 2010; Mische 2008). Importantly, the extent to which any given individual engages in automatic deliberation is an empirical question which demands the study of behavior across empirical domains as individuals may act mainly in accordance with Type 1 and Type 2 processes in many instances (see Evans 2018; Pennycook 2018). Empirically testing the extent to which individuals engage in Type 1 or Type 2 thinking thus presents an opportunity for sociologists to test assumptions about the way these processes are utilized by individuals in concrete situations rather than apply models such as the SDPM to various domains without questioning the extent to which they fruitfully make sense of those domains (see Cerulo 2018; Leschziner 2019; Moore 2017). ${ }^{10}$ Doing so will ensure that sociologists do not make mistaken assumptions about the nature of Type 1 and Type 2 processing in any given domain, as the division between these two processes as assumed by the SDPM will now be an open question rather than a default assumption (see Cerulo 2018; Leschziner 2019; Vila-Henninger 2015).

\section{Opting for hybridity}

To demonstrate the utility of the HDPM and PDPM over that of the SDPM and default-interventionist models, I first reconstruct the history through 
which recent debates about the automatic and habitual or deliberate and effortful nature of action emerged in sociology. As will be shown in Chapter 2, by reconstructing the history of current debates, I demonstrate how Swidler's (1986) rejection of seeing culture as a set of values (see Patterson 2014) had the unintended consequence of leading many sociologists to emphasize habitual aspects of thought and action heavily. By rejecting the "Parsonian" notion that action was shaped largely by deeply internalized cultural values, many sociologists using the SDPM came to frame the normative dimension of action as being a product of deep socialization but which could - albeit with a considerable amount of effort - be purposively and consciously overruled in any specific instance (see Vaisey 2009). In Chapters 3 and 4, I then demonstrate how looking for connections between Type 1 and Type 2 processing could be useful for sociologists (see Cerulo 2018; Leschziner 2015, 2019; Moore 2017; Vila-Henninger 2015) by examining data where individuals demonstrate a great deal of both types of processing: conversations between pedophiles on a public web forum; 39 secondary in-depth interviews with British seniors tasked to think about death, dying, and the prolongation of life; and 32 in-depth work-history interviews conducted with individuals living in the Toronto area who identify as working in sales who were asked a series of questions about their career trajectories.

In contrast to the assumption of largely predominate automatic processing, and in line with sociologists who see Type 1 and Type 2 processes as more blended and, at times, even synchronous (Cerulo 2018; Leschziner 2015; Leschziner and Green 2013; McDonnell 2014; McDonnell et al. 2017; Mische 2014; Moore 2017; Vila-Henninger 2015; Winchester 2016), I find that individuals muddle through dilemmatic topics using both Type 1 and Type 2 processes in parallel, cyclical, and often hybrid ways. Furthermore, I find that individuals' styles of deliberation are greatly shaped by both their surrounding culture (in the form of repertoires of ideas, norms, and other kinds of understandings of the topic in question) and their own life experiences (see Cerulo 2018; Leschziner 2015; McDonnell et al. 2017; Winchester and Green 2019). This manifests in the differing ways in which individuals across the three samples utilize Type 1 heuristics when discussing their respective topics, with some individuals responding more unproblematically (thus lending support to the SDPM) but most demonstrating more ambivalence and lack of resonance (see Benford 1997; McDonnell et al. 2017) as seen through their alternation between these heuristics. These findings support the tenets of the PDPM and the HDPM, as the PDPM explains moments when individuals cycle iteratively between heuristics (Pennycook 2018) and the HDPM explains moments when these cycles appear to be occurring at a Type 1 level (see Bago and De Neys 2017; Handley et al. 2011; Pennycook et al. 2014; Trippas et al. 2016a, 2016b).

While I find support for both the PDPM and the HDPM in each of my three cases, I overall find more support for the HDPM due to my data's greater demonstration of the process of automatic deliberation. As stated 


\section{Introduction}

earlier, according to this version of the dual process model, individuals possess multiple schemas for the same topics/stimuli, and thus may automatically draw on them in ways which lead to conflict - also automatically! - as they then must select which schema to use to continue thinking or acting effectively in a given situation. That is, unlike in the SDPM, where deliberation is posited as necessarily conscious and effortful, the HDPM posits that individuals possess multiple Type 1 heuristics or schemas for making sense of any given topic, thus assuming that deliberation can also be the result of automatic alternations between automatically triggered heuristics or schemas. When confronted with a stimulus, an individual may therefore be automatically impelled to deliberate over which Type 1 heuristic or schema to use, thus making this process of deliberation autonomous and unprompted rather than controlled and chosen. Thus, rather than frame cognition as primarily Type 1 or Type 2 (see Lizardo et al. 2016), I will showcase the fact that cognition tends to occur in a way which is irreducible to either of these two types (see Vila-Henninger 2015). In all three cases, individuals often come to rapidly alternate between schemas when discussing topics, demonstrating cognition which more fully fits Type 1 processing due to its autonomous, seemingly spontaneous, and cognitive economical qualities (see De Neys 2018), yet also fits Type 2 processing as this process leads individuals to think through their respective topics in an effortful manner to resolve the conflicts which were automatically made salient to them.

\section{Data and methods}

Throughout the book, I utilize qualitative methods to focus on the reasoning processes that individuals engage in as they think through topics rife with uncertainty. I focus on death and dying, pedophilia, and career decision-making, three cases which deal with topics that give rise to strong emotions for many individuals and which also frequently prompt them to further think through these emotional responses.

Case 1 - Death and Dying: For humans, nothing is more certain than death. However, individuals seldom expect to die and, when in their last years of life, often find themselves at a loss in terms of how to make sense of the fact that their lives will end (Copp 1998). Researchers ranging from sociologists (e.g., Glaser 1966; Strauss 1970; Walter 2003) to psychiatrists (e.g., Kübler-Ross 1969; Van der Kolk 2014) have found that individuals tend to go through a stage-like process of making sense of death once they believe that death is near. Individuals move from fearing death to accepting it, with this path primarily being circumvented by intense feelings of sorrow, loss, and/or denial (Kübler-Ross 1969; Schucter and Zisook 2003). The study of death and dying is increasing in significance as populations across the globe are tending to become older. Now, in many parts of the world, they have access to life-prolonging strategies on the one hand, but also to physicianassisted death on the other hand (see Quill et al. 2016; Seymour 2003). 
To examine death and dying, I use a publicly available set of 39 in-depth interviews conducted by Jane Seymour (2003) with individuals over the age of 65 who were tasked to think about end-of-life decisions. ${ }^{11}$ The main aim of the study was primarily to examine what older individuals thought about recent technologies that were designed to aid in resuscitation efforts. Questions moved from issues of these technologies, however, to broader questions about the nature of life prolongation. Data collection took place from 2001 to 2002 in Sheffield, UK. The data set includes transcripts of all interviews, and pseudonyms are used throughout.

Interviewees were stratified by age (35\% between the ages of 65 and 74 ; $33 \%$ between the ages of $75-85$, and $32 \%$ age 85 and over), gender (female: $64 \%$, male: $36 \%$ ), neighborhood deprivation (low: $46 \%$, middle: $18 \%$, high: $36 \%$ ), and living arrangement (own home: $87 \%$, in a state facility: $13 \%$ ). All interviewees identify as "White British," as being healthy (not chronically or terminally ill), and were randomly sampled by a series of general practitioners in the Sheffield area who had many patients to sample from. Pseudonyms are used for all interviewees.

In these interviews, interviewees were given vignettes of two fictional individuals - Frank, a man with terminal lung cancer; and Margaret, a woman with Alzheimer's - who gradually become more ill throughout their respective narratives. They are first asked a series of questions about how Frank and Margaret might react to doctors' suggestions of using particular medical devices to prolong their lives. They are shown pictures of the devices and are told how and why they would be used to prolong either Frank's or Margaret's life. The interview then moves onto questions involving these characters ultimately making the final decision to either prolong their lives or to die "naturally" after having considered these various life prolongation tools and strategies.

Case 2 - Pedophilia: Pedophilia is typically defined as adult sexual attraction to minors, with further specifications made based on the age of the minor. Despite pedophilia's medical definition being the sexual attraction to prepubescent children (typically age 12 and under), it tends to be lumped in and conflated with hebephilia, the sexual attraction to pubescent children (typically age 13-15) (see Blanchard et al. 2009). Primarily based on studies of correctional samples of men, research on pedophilia tends to converge on the claim that it is a sexual orientation that cannot be changed (Seto 2009). Given the fact that pedophilia is illegal, however, this sexual orientation causes great amounts of distress for individuals experiencing attraction to minors (Goode 2010). While some pedophiles demonstrate acceptance of their sexual preferences, the majority tend to demonstrate disgust and rejection toward them (see Seto 2009). Because of the social taboos and the disgust often elicited by the very mentioning of pedophilia, scholars have argued that more research on pedophiles who are neither active nor have been arrested for this offense is needed (Seto 2009). 
To study pedophilia, I conducted content analysis of conversations between non-active pedophiles (individuals who self-identify as pedophiles but do not act on their sexual desires for minors) on an American, publicly accessible chat forum that is open to anyone interested in mental health which I will be calling "WebHelpMe." 12 This forum is designed to enable individuals experiencing a variety of mental health issues - ranging from depression, to eating disorders, to sexual disorders (paraphilias) - to chat with both one another and with both professional and non-professional individuals interested in helping and supporting them. ${ }^{13}$ There are approximately 100,000 members, and the site has been live since the year 2000. The web forum has an array of sub-forums, all of which are related to psychological issues and support services. The sub-forum I focused on is the "Paraphilia" section. In this section, individuals create "threads" or conversation-style posts in which they ask questions about various sexual desires and problems that they are experiencing. Within this section, I focus exclusively on threads in which the primary conversation taking place is about sexual attraction to minors.

I analyze 20 threads, within which there are a total of 474 individual posts (23.7 posts per thread, each an average of about two paragraphs in length, on average) made by approximately 80 members of the website. All but four of the posters identify as men, with the average age being 27 years old. Socio-economic status (SES) is seldom discussed (only 14 of the individuals made reference to their SES in any of their posts), but those who did disclose their SES tended to be "middle-class" (10 out of 14 identified as such, with 2 identifying as working-class or poor and 2 identifying as wealthy). Of these 80 members, the bulk (about $60 \%$ ) of the posts I analyze come from about 15 of these individuals. The remaining 65 individuals tend to post infrequently, with 30 posting only once, 27 posting fewer than 2 times, and 8 posting fewer than 5 times. Pseudonyms are used to protect members' privacy, and all direct quotes are paraphrased.

Case 3 - Career Decision-making: Work is a cornerstone of postindustrial society but has greatly changed with recent advances in information technology. While individuals have tended to remain committed to a single employer for the bulk of their working lives, they now tend to have an average of 11.9 careers before retiring (U.S. Department of Labor, Bureau of Labor Statistics 2017). Although many individuals have seemingly embraced this new economic situation, there are many who have not (see Eby et al. 2003), a fact that is further reflected by increasing levels of job dissatisfaction around the world (Clifton 2017). This makes career decisions both more frequent and more ambivalent for individuals. Rather than climb the job ladder at a relatively slow and happy pace, individuals are increasingly making latticelike moves to lateral positions (see Benko and Anderson 2010) in a manner that often leaves them less engaged and uncertain as to their future employment prospects (Clifton 2017; Ibarra 2004; Moses 1997). 
To study career decision-making, I analyze a series of in-depth interviews that I conducted with salespersons located in Toronto, Canada. Data for this project were collected over an eight-month period in 2016-2017. Interviewees were recruited using the popular classified advertisement website "Craigslist." An advertisement was placed in the "volunteers" section of the website, which asked for individuals currently employed in sales if they would be willing to be interviewed. Thirty-two interviewees were recruited. They had a wide variety of work and educational histories and were all employed in sales jobs at the time of the interview. Twenty interviewees identify as male and 12 as female. The majority of interviewees identify as white $(N=19)$, with other interviewees identifying as black $(N=5)$, Asian $(N=4)$, Hispanic $(N=2)$, Indigenous $(N=1)$, and mixed race $(N=1)$. Twelve interviewees are between the ages of 20 and 29, 10 between 30 and 39, 5 between 40 and 49,4 between 50 and 59, and 1 over 65 years of age.

Interviews were semi-structured and in-depth, focusing on the core theme of how individuals find meaning at work and conceptualize their own career trajectories. Interviews began with a series of questions about the interviewees' work history, moved onto current employment, and ended with a discussion about expectations about the future. Interviews ranged from one to three hours, with the average length being approximately two hours. Several probes were used to unpack what work meant to each interviewee, as well as to flesh out the impact and interpretation of different life events for interviewees on their career trajectories. The use of probes evolved after each interview, with interviews becoming more conversational both as they each progressed and as overall from interview to interview.

\section{Summary of data and methods}

Each of these samples is discussed at greater length in their respective chapters in terms of sample construction and coding. As will be shown, common in all three sources of data is rich amounts of deliberation. Arguments among posters and explicitly stated identity crises in the web forum, questions about the experience of unmet expectations in the primary interviews on career decision-making, and the use of vignettes in the secondary qualitative data on death and dying all created fertile grounds for individual reflection and deliberation about topics which, more often than not for the posters and interviewees, appeared fundamentally dilemmatic.

Because of my emphasis on how schemas and frames are used in all three sources of data, I analyze the data using narrative analysis (Hollway and Jefferson 1997). In this approach, researchers tend to be interested in the reasoning processes that interviewees engage in and how these processes take specific shapes as trajectories (Hollway and Jefferson 1997). This approach is key to my analysis as I am indeed interested in examining when, how, and for how long individuals utilize specific schemas and frames 
(see Wood et al. 2018) in my three empirical domains. ${ }^{14}$ Inspired by Bago and De Neys (2017, 2019), I examine my data with an eye for the duration of the use of any given schema or frame. That is, rather than inventory the frequency of the use of schemas and frames - which is often done in sociological studies (for schemas e.g., Baumann and De Laat 2012; Baumann and Ho 2014; Epstein 2007; for frames e.g., Bleich 2002) - I examine how and why particular schemas and frames are used when making sense of dilemmatic topics in an effort to delineate the processes by which these heuristics resonate with and, in turn, become motivating factors for individuals (see McDonnell et al. 2017; Vila-Henninger 2015; Winchester and Green 2019). This process involves examining the use of schemas and frames temporally, gauging the extent to which individuals remain steadfast in their use of one particular schema or frame or show more alternation and/or ambivalence in their uses.

By examining how individuals reason through three different topics, I am able to analytically compare across multiple cases the process of automatic deliberation as it emerged in these data. This method of analytical triangulation is inspired by Vaughan's (2004:329) method of "analogical theorizing," which is designed to compare similar processes across different substantive topics to strengthen theoretical explanations and the generalizability of claims. Doing so also enabled me to leverage the strengths of each of the three cases in terms of how they provide me with access to individuals' thought processes. The data on death and dying enable me to analyze the extent to which schemas about life and death resonate with life experiences in the context of an interview; the data on pedophilia enable me to analyze how widely shared frames impact how individuals both seek help for and talk about this on a self-help web forum; and in my interviews with Canadians working in sales, I can more directly gauge the extent to which individuals quickly answered questions - demonstrating Type 1 processing in action or more carefully and slowly articulated their responses - demonstrating Type 2 processing (see Pennycook 2018). Comparisons across cases were made in regard to the kinds of cultural information used, the thought processes in which this information surfaced, and the contexts in which interviewees used this information. As such, each set of data provides me with access to different reasoning contexts and contents - individuals thought through three different topics in three different settings, each equipped with its own "emotional landscape" (Pugh 2013:42) which impacted the resonance of the heuristics being analyzed and the kinds of life experiences used to both drum up and fill in these cognitive aids (see Wood et al. 2018).

\section{Chapter outlines}

In Chapter 2, I argue that the long-standing tension between research which focuses on the dispositional qualities of thought and action and research which focuses on its situational qualities has recently resulted in the 
widespread use of an untenable model of thought and action: the defaultinterventionist SDPM (e.g., Vaisey 2009). To demonstrate the issues with this model, which asserts that cognitions occur either unconsciously and automatically or consciously and deliberately, I examine a topic that has been known to elicit both automatic and deliberate cognitions due to its dilemmatic nature: death and dying. Through analysis of 39 secondary, indepth interviews with seniors who have been tasked to think about death, dying, and resuscitation, I find that interviewees tend to automatically work their way through three phases of reasoning to questions posed to them about these issues: consultation, comfort and well-being, and the value of life. Using the terms automatic deliberation and cognitive path to describe this process of meaning-making, I assert that existing sociological explanations could benefit from taking into consideration both the emergent nature of individuals' perception of the worlds they live in and the iterative nature of the interview process.

In Chapter 3, I expand on my critique of the SDPM by examining how individuals alternate between heuristics when understanding a topic. This model, drawn from cognitive and social psychology (e.g., Haidt 2001, 2005), holds that all of an individual's cognitions can be classified as either unconscious and automatic or conscious and deliberate (see Cerulo 2018; Leschziner 2019; e.g., Haidt 2001, 2005; Vaisey 2009). Moreover, given the onerous nature of conscious and deliberate thinking, the model posits that individuals engage in unconscious and automatic thinking most often. Key in the use of this model is the idea that both of these forms of thinking Type 1 and Type 2 processing - are entirely discrete from one another. The individual mind is seen as possessing two types of processing, and, in extension, thinking is seen as being strictly unconscious and automatic or conscious and deliberate (see Lizardo et al. 2016). Despite being challenged by researchers such as Evans (2012) in psychology and Leschziner (2015) and Leschziner and Green (2013) in sociology for erroneously parsing processes which both fundamentally at a neural level may overlap and at a phenomenological level overlap in my case, the SDPM is still frequently used in sociological inquiry (see Lizardo et al. 2016).

To demonstrate how the SDPM parses cognitive processes which should be conceived as being interconnected in many cases, I conducted a comparative study on a topic that brings the confluence of unconscious and conscious influences on thinking to the fore: pedophilia. While non-active pedophiles may indeed have largely habitual, unconscious sexual orientations, due to widespread social taboos about this sexual orientation, these individuals frequently bring their sexual orientations to consciousness - they must think through their sexuality frequently as they are both demonized by the public and unable to legally act upon their sexual desires. Through the examination of conversations between pedophiles on a psychological selfhelp web forum, I find that non-active pedophiles' attitudes toward their sexualities are continually renegotiated using both widely shared beliefs 
about pedophilia and these individuals' own unique experiences. Based on this finding, I argue that pedophilia can be seen as a reflectively managed desire: an unconscious disposition which, due to the widespread sanctioning of pedophilia in contemporary Western society, is frequently brought to consciousness and, as a result, often changed. I extend this argument to support the HDPM over the SDPM, as the reflective management of desire the active negotiation of an unconsciously held publicly damned sexual orientation, in this case - demonstrates how individuals simultaneously engage in unconscious and conscious processing to make sense of dilemmatic situations.

To further refine my focus on how individual thought processes have both unconscious and conscious dimensions, in Chapter 4, I conduct a comparative study of how individuals draw on widespread understandings of two very different domains of their lives: death and dying, and career decisionmaking. By contrasting secondary interviews about dying and resuscitation decisions with the interviews that I conducted on employment and career planning, I found that individuals demonstrated a blended use of Type 1 and Type 2 processing when discussing both of these topics. Widespread understandings were drawn upon - such as attitudes toward the importance of autonomy juxtaposed with community and family concerns in the case of death, and attitudes toward livelihood and personal development in the case of employment - but were endowed with personal meaning as they were alternated between and reflected upon within the interview process in a seemingly spontaneous manner. In the case of employment, this process extended beyond the interview, as interviewees relayed to me their ongoing frustrations with their careers, feelings which often caused them to ebb and flow in terms of how they viewed their work, their aspirations, and their futures. This finding is important in that it shows that particular schemas do serve to shape how individuals consider death and employment, but they do so by enabling them to think through these ideas in patterned ways rather than strictly shaping what they think about them (see Margolis 1987). My analysis therefore sheds light on how schemas may direct cognition in a much more open-ended, unpredictable manner than is often assumed. Moreover, I demonstrate that schemas may do so as they shift from undeclared, tacit routines and habits to declared, explicit knowledge as observed in the interview setting. I therefore extend current research on the process of how frames resonate with individuals (McDonnell et al. 2017) by examining how individuals switch between schemas and frames when thinking through topics that they perceive to be dilemmatic.

In the concluding chapter, I reinforce the argument made in the introduction that models which account for closer interaction between Type 1 and Type 2 processes in sociological inquiry are needed given the findings in my three empirical chapters. By attending to how automatic thinking patterns structure more deliberate ones, I demonstrate how utilizing recent work done by cognitive and social psychologists (e.g., Ackerman and Thompson 
2017; De Neys 2018; Evans and Stanovich 2013; Pennycook 2018; Trippas et al. 2016a, 2016b) and, importantly, many sociologists who have actively made use of a variety of dual process models and theories (Leschziner 2015; Leschziner and Green 2013; McDonnell 2014; McDonnell et al. 2017; Mische 2014; Moore 2017; Vila-Henninger 2015; Winchester 2016) enables sociologists to study thinking in a way which can lead to the refinement of existing theories. Perhaps more importantly, doing so will also enable researchers to more accurately explain individual thinking across a wide array of empirical domains. This can be done by analyzing data through the theoretical lenses of the PDPM and HDPM which, contra the SDPM, assume more interconnection between Type 1 and Type 2 processes. Utilizing the analytical concept of cognitive path to examine data for such interconnections opens up space for the refinement of existing ideas regarding the extent to which individuals think about various topics, while engaging with the concept of automatic deliberation can similarly be used to test assumptions about the role that habit and effort play in how individuals think about various topics (see McDonnell et al. 2017; Silver 2011).

\section{Conclusion}

By deploying the concepts of automatic deliberation and cognitive path, throughout my book I demonstrate that the interconnections between Type 1 and Type 2 processes showcased across my three empirical cases demand that the SDPM ultimately be replaced by the PDPM and HDPM. While the SDPM indeed captures the basic process at play between alternations between more and less effortful thinking rather than consistently resolve the issues they were tasked to think about in a way which the SDPM would predict, individuals in all three cases tended to remain uncertain in regard to their views of these topics and, hence, demonstrate automatic ways of deliberating about the issues posed to them based on their evolving perspectives (see McDonnell et al. 2017). This should be taken as evidence that the SDPM may be well suited to the examination of problems that can be resolved using Type 2 cognition, but it is less useful for explaining dilemmas which cause individuals to augment their assumptions about the respective topic but never fully reach a resolution. This is because it makes this process appear more linear and sequential than it may actually be, and, indeed, as it was found to be for many individuals across my three cases who demonstrated great amounts of rapid alternations between Type 1 and Type 2 processing as well as blends of these processing in the light of subjectively perceived dilemmas. Future research can test the extent to which each of these models applies to empirical topics, keeping keen attention on the ways in which, while largely Type 1 or Type 2 in any single iteration of thinking, alternations between automatic and deliberate thought may be seen as importantly interwoven. Analyzing the extent to which this connection bears significance across different empirical domains can lead sociologists 
to potentially further disentangle the role that these processes play in shaping human behavior and, in turn, further refine our understanding of why individuals think as they do.

\section{Notes}

1 Acknowledging and echoing this division in emphasis, Lizardo (2017) argues that the study of culture can be categorized into studies of its personal or public qualities. In the former, culture can have non-declarative, tacit components or discursive, explicit components in what he calls declarative culture. In the latter, culture can be seen as more akin to collective representations that individuals are aware of but do not draw upon and integrate into their everyday lives to the same extent (Lizardo 2017). According to Lizardo (2017), categorizing individuals' uses of culture in these two ways enables sociologists to better understand how personal uses of culture tend to be tacit and non-declarative, shaping action in habitual ways, or articulable and declarative, consciously useable by individuals.

2 I will use Type rather than System throughout, as the former is now widely used by psychologists (see Evans and Stanovich 2013; Leschziner 2019). Moreover, I will use the terms Type 1 and Type 2 throughout this book as I follow cognitive psychologists who have moved away from the terms automatic and deliberate as they see these terms as misleading (see Leschziner 2019).

3 However, the dual process model itself is fragmented in that many versions of it have been formulated based on assumptions about the nature of autonomous or unconscious and controlled or conscious processing (Ackerman and Thompson 2017; Chaiken 1980; De Neys 2018; Evans 2018; Evans and Stanovich 2013; Pennycook 2018; Smith and DeCoster 2000; Thompson 2009).

4 Because schemas are personally developed, adaptive, and flexible, however, the same publically available frames may result in the development of different schemas for different individuals (see Wood et al. 2018). That is, individuals may schematize frames differently based on their particular social context.

5 For successful examples of bridging between dispositional and situational accounts unrelated to uses of the SDPM but theoretically similar, see Eliasoph and Lichterman (2003), Mische (2008).

6 This combination follows Cerulo's (2018: 384) call that the interconnections between non-declarative and declarative personal culture need to be examined across a wider variety of empirical cases "to determine the contexts in which interdependence versus independence rule the relationship between elements of personal culture." As will be shown, my use of dual process models which make different assumptions about the extent to which Type 1 and Type 2 processes are connected addresses Cerulo's (2018) call by enabling me to map out the extent to which individuals' iterations about their respective topics demonstrate either parallel or blended schematic and frame-based, or Type 1 and Type 2, reasoning.

7 Indeed, it will be demonstrated throughout this book that much of the reason for the temporal expansion of problems is that individuals schematize frames and frame schemas as fundamentally unresolvable due to perceived contradictions. For example, the frame of the "pedophile monster" makes a pedophilic desire dilemmatic for individuals because they have schematized the idea that individuals do not choose their sexual preferences. If this latter idea had not been schematized - if, as will be shown, the person believes that sexual orientations are arbitrary social constructions that are contingent solely on social norms and taboos - then the frame will merely be a label lacking any personal resonance; it can be disregarded as irrelevant, rather than forcing the individual to grapple with it at a Type 1, logical level (see De Neys 2018). 
8 For example, when reading this text, the reader may automatically draw upon their accumulated knowledge about sociology, cognition, or academic writing. Hopefully, this automatic selection process will aid the reading of this text rather than cause the reader to either abandon the process or deliberate to override their automatically chosen heuristic - for example, reading the paper with an eye for logical argumentation but, given the incoherence of the text, forcing themselves to switch to a more empathic mode of perception (e.g., looking for completion rather than competence).

9 This finding contradicts the assumption made by proponents of the SDPM that deliberate/Type 2 thinking is most often used to override automatic/Type 1 thinking (see Cerulo 2018; Leschziner, 2019; Lizardo 2017; Lizardo et al. 2016). Rather than engage in deliberate thought to resolve issues raised by automatic processes, Bago and De Neys $(2017,2019)$ found that individuals are often more accurate when relying on automatic processing, but they often reinforce their automatic thoughts rather than contradict them when engaging in deliberate processing. This fits research on expertise, which will be discussed later in the book, which asserts that once individuals become sufficiently proficient in a given domain, they tend to act efficiently and expertly by relying on automatic processing rather than on deliberate processing. This is most clear when analyzing athletes (see Latinjak et al. 2014, 2016; Van Raalte et al. 2016) and chefs (e.g., Leschziner 2015), as these individuals come to rely on habitual ways of competing and cooking, respectively, and in doing so avoid much of the cognitive overload and attendant frustration that new incumbents in these fields tend to face.

10 Indeed, Evans (2018) claims that psychologists must continue to conduct experiments not only to gauge the extent to which individuals draw on more or less Type 1 or Type 2 processes when given tasks to complete but also to further dispel myths about Type 1 processes as necessarily being biased and belief-based and Type 2 processes as being necessarily more accurate, logical, and abstract. Essential in his claim is that Type 1 cognitions may, in fact, be quite logical, and Type 2 processes, due to being called forth when individuals perceive the need to use them, may indeed be quite context-specific.

$11 \mathrm{https} / / /$ beta.ukdataservice.ac.uk/datacatalogue/studies/study?id=4840\&type= Data\%20catalogue.

12 Following the observations of an anonymous reviewer, I am using a pseudonym to protect the identities of the Forum posters.

13 Some individuals do not seek to support experiencing mental health issues on the forum. Instead, they "troll" or antagonize these individuals and are subsequently reported to the forum moderators and banned from the forum.

14 Throughout this book, I follow Wood et al.'s (2018) claim that schemas represent personal, non-declarative, or Type 1 forms of culture that individuals develop and automatically use to think through topics, whereas frames represent publicly shared, declarative, or Type 2 forms of culture that individuals deliberately use to think through topics.

1 The version of the model that Vaisey (2009) uses is referred to as the sociological dual process model (SDPM) throughout the chapter (Vila-Henninger 2015). It is based on the default-interventionist dual process model, which assumes that Type 1 and Type 2 processes operate discretely in a dualistic manner.

2 The inference I am making here must be taken with some caution, however, as individuals do not consciously think about all of the automatic decisions that they make (see Kahneman 2011; Vaisey 2009). The data I am analyzing gave me access to schematic understandings of death and dying which were used in the context of an interview. As such, interviewees were probed and asked to expand on their answers. Without such probing, these ideas may not have been forced into consciousness and thus made actively intuitable - they may have simply given answers and not thought much about them after the fact. 
1 This process of imitation indeed mirrors DiMaggio and Powell's (1983) concept of institutional isomorphism, as the dominance of norms about heterosexual marriage is embedded in myriad institutions, ranging from the family, to the school, to objects of consumption. Due to the diffuse nature of these norms, individuals' personal trajectories become more similar in terms of the sequence of life events - opting for a long-term, monogamous relationship, which will develop into marriage and procreation shortly after postsecondary education is attained, being the dominant trajectory.

2 Following the observations of an anonymous reviewer, I am using a pseudonym to protect the identities of the forum posters.

3 Some individuals do not seek to support experiencing mental health issues on the forum. Instead, they "troll" or antagonize these individuals, and are subsequently reported to the forum moderators and banned from the forum.

4 Since I limited my sample to threads within the topic of pedophilia, I examined all threads - even those without explicit references made to pedophilia - as I assumed that posts made within this topic field would be about pedophilia. As stated earlier, I chose to focus more on threads where posters discussed their attitudes toward and experiences of having pedophilic desires.

5 For individuals who felt more repulsed and/or burdened by their desires, the Nature frame was used more often, as will be shown when discussing the Nurture and Culture frames whereby these desires are seen as either the product of socialization or are neutral in and of themselves but have been deemed as cultural taboos, respectively.

6 This inability to or difficulty inherent in consciously thinking away one's non-declarative understandings is supported by research on posttraumatic stress disorder (PTSD) which has found that the very experience of PTSD is marked by the perception of being unable to control automatic recollections of traumatic experiences (Van der Kolk 2014). Pedophiles in my sample appeared similarly unable to control their fantasies about minors (see also Langevin et al. 1998) and often reflected on how their strategies for doing so tended to only make them feel worse about their sexual desires.

7 While some sociologists using the sociological dual process model do not rely on this assumption in their work (e.g., Danna-Lynch 2010; Harvey 2010; Leschziner 2015; Leschziner and Green 2013; McDonnell 2014; McDonnell et al. 2017; Mische 2014; Moore 2017; Vila-Henninger 2015; Winchester 2016), the sociological dual process model spearheaded by Vaisey (2009) relies heavily on this assumption due to its emphasis on early learned moral dispositions (see also Miles 2015).

1 Both findings, however, must be taken with caution as schemas crystallize over long periods of time and are hard to abandon once formed, while discursive frames can be acquired rapidly but discarded with ease (see Wood et al. 2018). Longitudinal research could help flesh out when, why, and how such "schema to frame" and "frame to schema" switches stick and when they do not.

2 Scholars alternate between the term "schemata" and "schemas" for the plural of schema. I have chosen to use "schemas" as that is the more common usage among contemporary sociologists (e.g., Vaisey 2009).

3 Critical of this move, Swidler (2008:617-618) asserts that sociologists should study how such schemas are "organized as they are" and, as such, become taken-for-granted in particular contexts rather than focus on how, once internalized, they come to shape behavior.

4 Vignettes have been used for similar purposes by sociologists such as Ann Swidler (2001). Swidler (2001) used vignettes about married individuals in an effort to elicit tacit assumptions that individuals might make when making decisions for themselves but would feel the need to justify when making these choices for others. This added specificity to one's answer will help me establish just how and why certain schemas apply to an interviewee's answer and how and why oth- 
ers do not. For instance, if an interviewee were to state that Frank would likely want to end his life due to being uncomfortable, the fact that they are making this decision on Frank's behalf may prompt the interviewee to give additional explanation for why exactly this may be the case.

5 Categorizing interviewees in this way enabled me to compare interviewees based on how deliberative they were overall, when it came to thinking through their careers. One of my most immediate findings when conducting the interviews was that interviewees varied greatly in this regard, with some interviewees demonstrating great deals of unprompted self-assessment but others answering interview questions in relative disconnected, unreflective ways.

\section{References}

Ackerman, Rakeft, and Valerie A. Thompson. 2017. "Meta-Reasoning: Shedding Metacognitive Light on Reasoning Research.” Pp. 1-15 in The Routledge International Handbook of Thinking and Reasoning, edited by Linden J. Ball and Valerie A. Thompson. New York: Routledge.

Archer, Margaret S. 2007. Making our Way through the World: Human Reflexivity and Social Mobility. Cambridge: Cambridge University Press.

Bago, Bence, and Wim De Neys. 2017. "Fast Logic? Examining the Time Course Assumption of Dual Process Theory." Cognition 158: 90-109.

Bago, Bence, and Wim De Neys. 2019. "The Smart System 1: Evidence for the Intuitive Nature of Correct Responding in the Bat-and-Ball Problem." Thinking and Reasoning 3: 257-299.

Baumann, Shyon, and Kim de Laat. 2012. "Socially Defunct: A Comparative Analysis of the Underrepresentation of Older Women in Advertising." Poetics 40: 514-541.

Baumann, Shyon and Loretta Ho. 2014. "Cultural Schemas for Racial Identity in Canadian Television Advertising.” Canadian Journal of Sociology 51: 152-169.

Bem, Sandra L. 1981. "Gender Schema Theory: A Cognitive Account of Sex Typing." Psychological Review 88(4): 354-364.

Benford, Robert. 1997. “An Insider's Critique of the Social Movement Framing Perspective." Sociological Inquiry 67(4): 409-430.

Benko, Cathleen, and Molly Anderson. 2010. The Corporate Lattice: Achieving High Performance in the Changing World of Work. Boston, MA: Harvard Business Review Press.

Betsch, Tilmann, and Andreas Glöckner. 2010. "Intuition in Judgment and Decision Making: Extensive Thinking without Effort." Psychological Inquiry 21(4): 279-294.

Blanchard, Ray, Amy D. Lykins, Diane Wherrett, Michael E. Kuban, James M. Cantor, Thomas Blak, Robert Dickey, and Philip E. Klassen. 2009. "Pedophilia, Hebephilia, and the DSM-V." Archives of Sexual Behavior 38(3): 335-350.

Bleich, Erik. 2002. "Integrating Ideas into Policy-Making Analysis: Frames and Race Policies in Britain and France." Comparative Political Studies 35(9): 1054-1076. 
Bourgois, Philippe, and Jeffrey Schonberg. 2009. Righteous Dopefiend. Los Angeles: University of California Press.

Chaiken, Shelly. 1980. "Heuristic versus Systematic Information Processing and the Use of Source versus Message Cues in Persuasion." Journal of Personality and Social Psychology 39: 752-766.

Cerulo, Karen A. 2018. "Scents and Sensibility: Olfaction, Sense-Making, and Meaning Attribution.” American Sociological Review 83(2): 361-389.

Clifton, Jim. 2017. “The World's Broken Workplace.” Gallup. Retrieved Online: https://news.gallup.com/opinion/chairman/212045/world-broken-workplace.aspx

Copp, Gina. 1998. "A Review of Current Theories of Death and Dying." Journal of Advanced Nursing 28(2): 382-390.

Cowen, Tyler. 2017. The Complacent Class: The Self-Defeating Quest for the American Dream. New York: St. Martin's Press.

Danna-Lynch, Karen. 2010. "Switching Roles: The Process of Mental Weighing." Poetics 38: 165-183.

De Neys, Wim. 2018. "Bias, Conflict, and Fast Logic: Towards a Hybrid Dual Process Future?” Pp. 46-65 in Dual Process Theory 2.0, edited by Wim De Neys. New York: Routledge.

Dewey, John. [1922]1988. John Dewey, the Middle Works, 1899-1924: Human Nature and Conduct, vol. 12. Carbondale: Southern Illinois University Press.

DiMaggio, Paul. 1997. "Culture and Cognition." Annual Review of Sociology 23: 263-287.

Eby, Lillian, Marcus Butts, and Angie Lockwood. 2003. "Predictors of Success in the Era of the Boundaryless Career." Journal of Organizational Behavior 24 689-708.

Eliasoph, Nina, and Paul Lichterman. 2003. "Culture in Interaction." American Journal of Sociology 108(4): 735-794.

Elqayam, Shira, and David Over. 2012. "Probabilities, Beliefs, and Dual Processing: The Paradigm Shift in the Psychology of Reasoning." Mind \& Society 11(1): 27-40.

Epstein, Cynthia Fuchs. 2007. "Great Divides: The Cultural, Cognitive, and Social Bases of the Global Subordination of Women." American Sociological Review 72: $1-22$.

Evans, Jonathan St. B. T. 2010. "Intuition and Reasoning: A Dual-Process Perspective." Psychological Inquiry 21(4): 313-326.

Evans, Jonathan St. B.T. 2012. "Spot the Difference: Distinguishing between Two Kinds of Processing." Mind and Society 11: 121-131.

Evans, Jonathan St. B. T. 2018. "Dual Process Theory: Perspectives and Problems." Pp. 137-156 in Dual Process Theory 2.0, edited by Wim De Neys. New York: Routledge.

Evans, Jonathan St. B. T., and Keith E. Stanovich. 2013. "Dual-Process Theories of Higher Cognition: Advancing the Debate.” Perspectives in Psychological Science 8: 223-241.

Ferreira, Mario B., Leonel Garcia-Marques, Stephen J. Sherman, and Jeffrey W. Sherman. 2006. "Automatic and Controlled Components of Judgment and Decision Making." Journal of Personality and Social Psychology 91(5): 797-813.

Frankish, Keith. 2012. "Dual Systems and Dual Attitudes." Mind and Society 11(1): 41-51.

Gerhardt, Uta. 2011. The Social Thought of Talcott Parsons: Methodology and American Ethos. London: Routledge.

Glaser, Barney G. 1966. "The Social Loss of Aged Dying Patients.” Gerontologist 
6: $77-80$.

Goode, Sarah D. 2010. Understanding and Addressing Adult Sexual Attraction to Children: A Study of Paedophiles in Contemporary Society. London and New York: Routledge.

Haidt, Jonathan. 2001. "The Emotional Dog and Its Rational Tail: A Social Institutionist Approach to Moral Judgment." Psychological Review 108: 814-834.

Haidt, Jonathan. 2005. The Happiness Hypothesis: Finding Modern Truth in Ancient Wisdom. New York: Basic Books.

Handley, Simon J., Stephen E. Newstead, and Dries Trippas. 2011. "Logic, Beliefs, and Instruction: A Test of the Default Interventionist Account of Belief Bias." Journal of Experimental Psychology: Learning, Memory, \& Cognition 37(1): 28-43.

Hansson, Robert O., Bruce N. Carpenter, and Sharon K. Fairchild. 2003. "Measurement Errors in Bereavement." Pp. 62-74 in Handbook of Bereavement: Theory, Research, and Intervention, edited by Margaret S. Stroebe, Wolfgang Stroebe, and Robert O. Hansson. Cambridge: Cambridge University Press.

Harvey, Daina C. 2010. "The Space for Culture and Cognition.” Poetics 35: 184-203.

Hollway, Wendy, and Tony Jefferson. 1997. "Eliciting Narrative through the InDepth Interview. Qualitative Inquiry 3(1): 53-70.

Ibarra, Herminia. 2004. Working Identity: Unconventional Strategies for Reinventing Your Career. Boston, MA: Harvard Business School Press.

Janet, Pierre. 1904. "L'Amnésie et la Dissociation des Souvenirs par L'Emotion." Journal de Psychologie 1: 417-453.

Kinder, Donald R. and Lynn M. Sanders. 1990. "Mimicking Political Debate with Survey Questions: The Case of White Opinion on Affirmative Action for Blacks." Social Cognition 8(1): 73-103.

Kübler-Ross, Elisabeth.1969. On Death and Dying. New York: Macmillan.

Lamont, Michele, and Ann Swidler. 2014. "Methodological Pluralism and the Possibilities and Limits of Interviewing." Qualitative Sociology 37(2): 153-171.

Latinjak, Alexander T., Antonis Hatzigeorgiadis, and Nikos Zourbanos. 2016. "Goal-Directed and Spontaneous Self-Talk in Anger- and Anxiety-Eliciting Sport-Situations." Journal of Applied Sport Psychology 29(2): 150-166.

Latinjak, Alexander T., Nikos Zourbanos, Victor Lopez-Ros, and Antonis Hatzigeorgiadis. 2014. "Goal-Directed and Undirected Self-Talk: Exploring a New Perspective for the Study of Athletes' Self-Talk." Psychology of Sport and Exercise 15(5): 548-558.

Leschziner, Vanina. 2015. At the Chef's Table: Culinary Creativity in Elite Restaurants. Stanford, CA: Stanford University Press.

Leschziner, Vanina. 2019. "Dual Process Models.” Pp. 169-191 in Oxford Handbook of Cognitive Sociology. Oxford: Oxford University Press.

Leschziner, Vanina, and Adam I. Green. 2013. "Thinking about Food and Sex: Deliberate Cognition in the Routine Practices of a Field." Sociological Theory 31: 116-144.

Lizardo, Omar. 2017. "Improving Cultural Analysis: Considering Personal Culture in Its Declarative and Nondeclarative Modes." American Sociological Review 82(1): 88-115.

Lizardo, Omar, and Michael Strand. 2010. "Skills, Toolkits, Contexts and Institutions: Clarifying the Relationship between Different Approaches to Cognition in Cultural Sociology." Poetics 38: 204-227. 
Lizardo, Omar, Robert Mowry, Brandon Sepulvado, Dustin S. Stoltz, Marshall A. Taylor, Justin Van Ness, and Michael Wood. 2016. "What Are Dual Process Models? Implications for Cultural Analysis in Sociology." Sociological Theory 34(4): 287-310.

Macchi, Laura, and Maria Bagassi. 2012. "Intuitive and Analytical Processes in Insight Problem Solving: A Psycho-Rhetorical Approach to the Study of Reasoning." Mind \& Society 11(1): 53-67.

Margolis, Howard. 1987. Patterns, Thinking, and Cognition: A Theory of Judgment. Chicago, IL: University of Chicago Press.

Martin, John Levi, and Matthew Desmond. 2010. "Political Position and Social Knowledge." Sociological Forum 25: 1-26.

McDonnell, Terence E. 2014. "Drawing Out Culture: Productive Methods to Measure Cognition and Resonance. Theory and Society 43(3-4): 247-274.

McDonnell, Terence E., Christopher A. Bail, and Iddo Tavory. 2017. "A Theory of Resonance." Sociological Theory 35: 1-14.

Mead, George Herbert. 1934. Mind, Self, \& Society: From the Standpoint of a Social Behaviourist, edited by Charles Morris. Chicago, IL: University of Chicago Press. Miles, Andrew. 2014. "Addressing the Problem of Cultural Anchoring: An IdentityBased Model of Culture in Action." Social Psychology Quarterly 77(2): 210-227.

Mische, Ann. 2008. Partisan Publics: Communication and Contention across Brazilian Youth Activist Networks. Princeton, NJ: Princeton University Press.

Mische, Ann. 2014. "Measuring Futures in Action: Projective Grammars in the Rio+20 Debates." Theory and Society 43: 437-464.

Moore, Rick. 2017. "Fast or Slow: Sociological Implications of Measuring DualProcess Cognition." Sociological Science 4: 196-223.

Moses, Barbara. 1997. Career Intelligence: Mastering the New Work and Personal Realities. Toronto: Stoddart.

Parsons, Talcott. 1949. The Structure of Social Action. New York: Free Press.

Patterson, Orlando. 2014. "Making Sense of Culture." Annual Review of Sociology 40: $1-30$.

Pennycook, Gordon. 2018. "A Perspective on the Theoretical Foundation of Dual Process Models.” Pp. 5-27 in Dual Process Theory 2.0, edited by Wim De Neys. New York: Routledge.

Pennycook, Gordon, Dries Trippas, Simon J. Handley, and Valerie A. Thompson. 2014. "Base Rates: Both Neglected and Intuitive." Journal of Experimental Psychology: Learning Memory and Cognition 40(2): 544-554.

Pugh, Allison. 2013. "What Good Are Interviews for Thinking about Culture? Demystifying Interpretive Analysis." American Journal of Cultural Sociology 1(1): 42-68.

Quill, Timothy E., Anthony L. Back, and Susan D. Block. 2016. "Responding to Patients Requesting Physician-Assisted Death: Physician Involvement at the Very End of Life." JAMA 315(3): 245-246.

Ramvi, Ellen, Julian Manley, Lynn Froggett, Anne Liveng, Aase Lading, Wendy Hollway, and Birgitta Haga Gripsrud. 2018. "The Visual Matrix Method in a Study of Death and Dying: Methodological Reflections." Psychoanalysis, Culture \& Society 24(1): 31-52.

Ridgeway, Cecilia L. 2009. "Framed before We Know It: How Gender Shapes Social Relations." Gender \& Society 23(2): 145-160. 
Schucter, Stephen R., and Sidney Zisook. 2003. "The Course of Normal Grief." Pp. 23-43 in Handbook of Bereavement: Theory, Research, and Intervention, edited by Margaret S. Stroebe, Wolfgang Stroebe, and Robert O. Hansson. Cambridge: Cambridge University Press.

Schwarz, Ori. 2015. "The Sound of Stigmatization: Sonic Habitus, Sonic Styles, and Boundary Work in an Urban Slum." American Journal of Sociology 121(1): 205-242.

Seto, Michael C. 2009. "Pedophilia." Annual Review of Clinical Psychology 5: 391-407.

Seto, Michael C. 2012. "Is Pedophilia a Sexual Orientation?" Archives of Sexual Behavior 41(1): 231-236.

Seymour, Jane. 2003. “Technology and 'Natural Death': A Study of Older People." Zeitschrift für Gerontologie und Geriatrie 36(5): 339-346.

Shepherd, Hana. 2011. "The Cultural Context of Cognition: What the Implicit Association Test Tells Us about How Culture Works." Sociological Forum 26(1): 121-143.

Silver, Daniel. 2011. "The Moodiness of Action." Sociological Theory 29(3): 199-222.

Sloman, Steven A. 2014. "Two Systems of Reasoning, an Update.” Pp. 69-79 in DualProcess Theories of the Social Mind, edited by J.W. Sherman, B. Gawronski, \& Y. Trope. Guildford Press.

Smith, Eliot R., and Jamie DeCoster. 2000. "Dual-Process Models in Social and Cognitive Psychology: Conceptual Integration and Links to Underlying Memory Systems." Personality and Social Psychology Review 4: 108-131.

Strauss, Anselm L. 1970. Anguish: The Case History of a Dying Trajectory. San Francisco: California Sociology Press.

Sun, Ron, and Robert C. Mathews. 2012. "Implicit Cognition, Emotion, and MetaCognitive Control.” Mind \& Society 11(1): 107-119.

Swidler, Ann. 1986. "Culture in Action: Symbols and Strategies." American Sociological Review 51(2): 273-286.

Swidler, Ann. 2001. Talk of love: How Culture Matters. Chicago, IL: University of Chicago Press.

Sykes, Gresham M., and David Matza. 1957. "Techniques of Neutralization.” American Sociological Review 22: 664-670.

Thompson, Valerie A. 2009. "Dual-Process Theories: A Metacognitive Perspective.” Pp. 171-195 in In Two Minds: Dual Processes and Beyond, edited by Jonathan St. B. T. Evans and K. Frankish. Oxford: Oxford University Press.

Thompson, Valerie A., and Ian R. Newman. 2018. "Logical Intuitions and Other Condundra for Dual Process Theories. Pp. 121-136 in Dual Process Theory 2.0, edited by Wim De Neys. New York: Routledge.

Trippas, Dries, Simon Handley, Michael Verde, and Kinga Morsanyi. 2016a. "Logic Brightens My Day: Evidence for Implicit Sensitivity to Logical Validity." Journal of Experimental Psychology: Learning, Memory, and Cognition 42(9): 1448-1457.

Trippas, Dries, Valerie Thompson, and Simon J. Handley. 2016b. "When Fast Logic Meets Slow Belief: Evidence for a Parallel-Processing Model of Belief Bias." Memory \& Cognition 45(4): 539-552.

Trippas, Dries, and Simon J. Handley. 2018. "The Parallel Processing Model of Belief Bias: Review and Extensions." Pp. 29-46 in Dual Process Theory 2.0, edited by Wim De Neys. New York: Routledge. 
Twenge, Jean M. 2017. iGen: Why Today's Super-Connected Kids Are Growing Up Less Rebellious, More Tolerant, Less Happy - And Completely Unprepared for Adulthood. New York: Atria Books.

U.S. Department of Labor, Bureau of Labor Statistics. 2017. "Number of Jobs, Labor Market Experience, and Earnings Growth: Results from a National Longitudinal Survey News Release.” Retrieved Online: https://www.bls.gov/news.release/ nlsoy.htm

Vaisey, Stephen. 2009. "Motivation and Justification: Toward a Dual-Process Theory of Culture in Action. American Journal of Sociology 114: 1675-1715.

Vaisey, Stephen, and Omar Lizardo. 2010. "Can Cultural Worldviews Influence Network Composition?" Social Forces 88: 1595-1618.

Van der Kolk, Bessel A. 2014. The Body Keeps the Score: Brain, Mind, and Body in the Healing of Trauma. New York: Viking.

Van der Kolk, Bessel A., and Rita Fisler. 1995. "Dissociation and the Fragmentary Nature of Traumatic Memories: Overview and Exploratory Study." Journal of Traumatic Stress 8(4): 505-525.

Van der Kolk, Bessel A., and Onno Van der Hart. 1991. "The Intrusive Past: The Flexibility of Memory and the Engraving of Trauma." American Imago 48(4): 425-454.

Van Raalte, Judy L., Andrew Vincent, and Britton W. Brewer. 2016. "Self-Talk: Review and Sport-Specific Model." Psychology of Sport and Exercise 22: 139-148.

Vaughan, Diane. 2004. "Theorizing Disaster: Analogy, Historical Ethnography, and the Challenger Accident." Ethnography 5(3): 315-347.

Vila-Henninger, Luis Antonio. 2015. "Toward Defining the Causal Role of Consciousness: Using Models of Memory and Moral Judgment from Cognitive Neuroscience to Expand the Sociological Dual-Process Model." Journal for the Theory of Social Behaviour 45: 238-260.

Walter, Tony. 2003. "Historical and Cultural Variants on the Good Death." British Medical Journal 327: 218-20.

Whitford, Josh. 2002. "Pragmatism and the Untenable Dualism of Means and Ends: Why Rational Choice Theory Does Not Deserve Paradigmatic Privilege." Theory and Society 31(3): 325-363.

Winchester, Daniel. 2016. "A Hunger for God: Embodied Metaphor as Cultural Cognition in Action." Social Forces 95(5): 85-606.

Winchester, Daniel, and Kyle Green. 2019. "Talking Yourself into It: How and When Accounts Shape Motivation for Action.” Sociological Theory 37(3): 257-281.

Wood, Michael Lee, Dustin S. Stoltz, Justin Van Ness, and Marshall A. Taylor. 2018. "Schemas and Frames." Sociological Theory 36(3): 244-261.

Altikriti, Anas, and Salam Al-Mahadin. 2015. "Muslim 'Hate Preachers' in British Tabloids: Constructing the British Self and the Muslim Other." European Journal of Cultural Studies 18(6): 620-638.

Archer, Margaret S. 2007. Making Our Way through the World: Human Reflexivity and Social Mobility. Cambridge: Cambridge University Press.

Archer, Margaret S. 2010. "Routine, Reflexivity, and Realism." Sociological Theory 28(3): 272-303.

Bago, Bence, and Wim De Neys. 2017. "Fast Logic? Examining the Time Course Assumption of Dual Process Theory." Cognition 158: 90-109.

Bago, Bence, and Wim De Neys. 2019. "The Smart System 1: Evidence for the Intuitive Nature of Correct Responding in the Bat-and-Ball Problem." Thinking and Reasoning 3: 257-299. 
Baumann, Shyon and Loretta Ho. 2014. "Cultural Schemas for Racial Identity in Canadian Television Advertising." Canadian Journal of Sociology 51: 152-169.

Bem, Sandra L. 1981. "Gender Schema Theory: A Cognitive Account of Sex Typing." Psychological Review 88(4): 354-364.

Berg, Justin M. 2014. "The Primal Mark: How the Beginning Shapes the End in the Development of Creative Ideas." Organizational Behavior and Human Decision Processes 125(1): 1-17.

Bloch, Maurice. 2015. In and Out of Each Other's Bodies: Theory of Mind, Evolution, Truth, and the Nature of the Social. New York: Routledge.

Bollas, Christopher. 1987. The Shadow of the Object. London: Free Association Books.

Bourdieu, Pierre. 1977. Outline of a Theory of Practice. Cambridge: Cambridge University Press.

Bourdieu, Pierre. 1984. Distinction: A Social Critique of the Judgment of Taste. Cambridge, MA: Harvard University Press.

Braun, Kathryn L., and Ana Zir. 2001. "Roles for the Church in Improving Endof-Life Care: Perceptions of Christian Clergy and Laity." Death Studies 25(8): 685-704.

Broom, Alex, and Emma Kirby. 2013. "The End of Life and the Family: Hospice Patients' Views on Dying as Relational." Sociology of Health \& Illness 35(4): 1-15.

Burawoy, Michael. 1998. "The Extended Case Method." Sociological Theory 16(1): 4-33.

Calhoun, Lawrence G., Richard G. Tedeschi. 2004. "The Foundations of Posttraumatic Growth: New Considerations.” Psychological Inquiry 15: 93-102.

Chernov, Nikolai, and Dmitry Dolgopyat. 2009. "The Galton Board: Limit Theorems and Recurrence." Journal of the American Mathematical Society 22(3): $821-858$.

Cerulo, Karen A. 2010. "Mining the Intersections of Cognitive Sociology and Neuroscience.” Poetics 38: 115-132.

Cerulo, Karen A. 2018. "Scents and Sensibility: Olfaction, Sense-Making, and Meaning Attribution.” American Sociological Review 83(2): 361-389.

Corr, Charles A. 1993. "Coping with Dying: Lessons That We Should and Should Not Learn from the Work of Elisabeth Kübler-Ross." Death Studies 17: 69-83.

Corr, Charles A. 2018. Elisabeth Kübler-Ross and the "Five Stages" Model in a Sampling of Recent American Textbooks. OMEGA - A Journal of Death and Dying 0(0): 1-29.

Danna-Lynch, Karen. 2010. "Switching Roles: The Process of Mental Weighing." Poetics 38: 165-183.

Decoteau, Claire L. 2016. "The Reflexive Habitus: Critical Realist and Bourdieusian Social Action.” European Journal of Social Theory 19(3): 1-19.

De Neys, Wim. 2018. "Bias, Conflict, and Fast Logic: Towards a Hybrid Dual Process Future?” Pp. 46-65 in Dual Process Theory 2.0, edited by Wim De Neys. New York: Routledge.

DiMaggio, Paul. 1997. "Culture and Cognition." Annual Review of Sociology 23: 263-287.

DiMaggio, Paul and Walter Powell. 1983. "The Iron Cage Revisited: Institutional Isomorphism and Collective Rationality in Organizational Fields." American Sociological Review 48: 147-160.

Durkheim, Emile. [1895]1982. The Rules of Sociological Method and Selected Texts on Sociology and Its Method. S. Lukes (Ed.). New York and Toronto: The Free Press. 
Durkheim, Emile. [1897]1951. Suicide. New York: Free Press.

Eliasoph, Nina, and Paul Lichterman. 2003. "Culture in Interaction." American Journal of Sociology 108(4): 735-794.

Elder-Vass, Dave. 2010. The Causal Power of Social Structures: Emergence, Structure and Agency. Cambridge: Cambridge University Press.

Evans, Jonathan St. B. T. 2010. "Intuition and Reasoning: A Dual-Process Perspective." Psychological Inquiry 21(4): 313-326.

Evans, Jonathan St. B.T. 2012. "Spot the Difference: Distinguishing between two Kinds of Processing." Mind and Society 11: 121-131.

Frank, Michael J., Michael X. Cohen, and Alan G. Sanfrey. 2009. "Multiple Systems in Decision Making: A Neurocomputational Perspective." Current Directions in Psychological Science 18(2): 73-77.

Gale, Anthony. 1983. "Electroencephalographic Studies of Extraversion-Introversion: A Case Study in the Psychophysiology of Individual Differences." Personality and Individual Differences 4: 371-380.

Giddens, Anthony. 1984. The Constitution of Society. Berkley: University of California Press.

Haidt, Jonathan. 2001. "The Emotional Dog and Its Rational Tail: A Social Institutionist Approach to Moral Judgment.” Psychological Review 108: 814-834.

Hallberg, Ingallil Rahm. 2004. "Death and Dying from Old People's Point of View: A Literature Review." Aging Clinical and Experimental Research 16(2): 87-103.

Handley, Simon J., and Dries Trippas. 2015. "Dual Processes and the Interplay between Knowledge and Structure: A New Parallel Processing Model.” Psychology of Learning and Motivation - Advances in Research and Theory 62: 33-58.

Handley, Simon J., Stephen E. Newstead, and Dries Trippas. 2011. "Logic, Beliefs, and Instruction: A Test of the Default Interventionist Account of Belief Bias." Journal of Experimental Psychology: Learning, Memory, \& Cognition 37(1): 28-43.

Hansson, Robert O., Bruce N. Carpenter, and Sharon K. Fairchild. 2003. "Measurement Errors in Bereavement." Pp. 62-74 in Handbook of Bereavement: Theory, Research, and Intervention, edited by Margaret S. Stroebe, Wolfgang Stroebe, and Robert O. Hansson. Cambridge: Cambridge University Press.

Harvey, Daina C. 2010. “The Space for Culture and Cognition.” Poetics 35: 184-203.

Helm, Rebecca K., Michael J. McCormick, and Valerie F. Reyna. 2017. "Expert Decision-Making: A Fuzzy-Trace Theory Perspective.” Pp. 289-303 in The Routledge International Handbook of Thinking and Reasoning, edited by Linden J. Ball and Valerie A. Thompson. New York: Routledge.

Hollway, Wendy, and Tony Jefferson. 1997. "Eliciting Narrative through the InDepth Interview. Qualitative Inquiry 3(1): 53-70.

Inglehart, Ronald, and Wayne E. Baker. 2000. "Modernization, Cultural Change and the Persistence of Traditional Values." American Sociological Review 65: $19-51$.

Ivey, Allen E., Mary Bradford Ivey, and Carlos P. Zalaquett. 2017. Intentional Interviewing and Counseling: Facilitating Client Development in a Multicultural Society, Ninth Edition. Pacific Grove, CA: Brooks/Cole - Thomson Learning.

Jerolmack, Colin, and Shamus Khan. 2014. "Talk Is Cheap: Ethnography and the Attitudinal Fallacy.” Sociological Methods \& Research 43(2): 178-209.

Joas, Hans. 1996. The Creativity of Action. Chicago: The University of Chicago Press. 
Johnson, Debra L., John S. Wiebe, Sherri M. Gold, Nancy C. Andreasen, Richard D. Hichwa, G. Leonard Watkins, and Laura L. Boles Ponto. 1999. "Cerebral Blood Flow and Personality: A Positron Emission Tomography Study." American Journal of Psychiatry 156(2): 252-257.

Kahneman, Daniel. 2011. Thinking, Fast and Slow. Toronto: Doubleday Canada.

Kübler-Ross, Elisabeth.1969. On Death and Dying. New York: Macmillan.

Lamont, Michele, and Ann Swidler. 2014. "Methodological Pluralism and the Possibilities and Limits of Interviewing." Qualitative Sociology 37(2): 153-171.

Lamont, Michel, Stefan Beljean, and Matthew Clair. 2014. "What Is Missing? Cultural Processes and Causal Pathways to Inequality." Socio-Economic Review 12: 573-608.

Latinjak, Alexander T., Antonis Hatzigeorgiadis, and Nikos Zourbanos. 2016. "Goal-Directed and Spontaneous Self-Talk in Anger- and Anxiety-Eliciting Sport-Situations.” Journal of Applied Sport Psychology 29(2): 150-166.

Latinjak, Alexander T., Nikos Zourbanos, Victor Lopez-Ros, and Antonis Hatzigeorgiadis. 2014. "Goal-Directed and Undirected Self-Talk: Exploring a New Perspective for the Study of Athletes' Self-Talk." Psychology of Sport and Exercise 15(5): 548-558.

Leschziner, Vanina. 2015. At the Chef's Table: Culinary Creativity in Elite Restaurants. Stanford, CA: Stanford University Press.

Leschziner, Vanina, and Adam I. Green. 2013. "Thinking About Food and Sex: Deliberate Cognition in the Routine Practices of a Field. Sociological Theory 31: $116-144$.

Lizardo, Omar. 2017. "Improving Cultural Analysis: Considering Personal Culture in Its Declarative and Nondeclarative Modes." American Sociological Review 82(1): $88-115$.

Lizardo, Omar, and Michael Strand. 2010. "Skills, Toolkits, Contexts and Institutions: Clarifying the Relationship between Different Approaches to Cognition in Cultural Sociology." Poetics 38: 204-227.

Lizardo, Omar, Robert Mowry, Brandon Sepulvado, Dustin S. Stoltz, Marshall A. Taylor, Justin Van Ness, and Michael Wood. 2016. "What Are Dual Process Models? Implications for Cultural Analysis in Sociology." Sociological Theory 34(4): 287-310.

Lorenz, Edward N. 2005. The Essence of Chaos. Washington, DC: University of Washington Press.

Mandler, Jean M. 1979. "Categorical and Schematic Organization of Memory." Pp. 259-299 in Memory Organization and Structure, edited by C. R. Puff. New York: Academic Press.

Mannix, Kathryn. 2017. With the End in Mind: Dying, Death, and Wisdom in an Age of Denial. London: William Collins.

Martin, Andrew J. 2016. Using Load Reduction Instruction (LRI) to Boost Motivation and Engagement. Leicester: British Psychological Society.

Martin, John Levi, and Matthew Desmond. 2010. "Political Position and Social Knowledge." Sociological Forum 25: 1-26.

McDonnell, Terence E., Christopher A. Bail, and Iddo Tavory. 2017. "A Theory of Resonance." Sociological Theory 35: 1-14.

Mead, George Herbert. 1934. Mind, Self, \& Society: From the Standpoint of a Social Behaviourist, edited by Charles Morris. Chicago, IL: University of Chicago Press.

Miles, Andrew. 2014. "Addressing the Problem of Cultural Anchoring: An IdentityBased Model of Culture in Action.” Social Psychology Quarterly 77(2): 210-227. 
Mische, Ann. 2008. Partisan Publics: Communication and Contention across Brazilian Youth Activist Networks. Princeton, NJ: Princeton University Press.

Moore, Rick. 2017. "Fast or Slow: Sociological Implications of Measuring DualProcess Cognition.” Sociological Science 4: 196-223.

Park, Crystal L., Lawrence H. Cohen, and Renee L. Murch. 1997. "Assessment and Prediction of Stress-Related Growth.” Journal of Personality 64(1): 71-105.

Parkes, Colin Murray. 2003. "Bereavement as a Psychosocial Transition: Processes of Adaptation to Change." Pp. 91-101 in Handbook of Bereavement: Theory, Research, and Intervention, edited by Margaret S. Stroebe, Wolfgang Stroebe, and Robert O. Hansson. Cambridge: Cambridge University Press.

Patterson, Orlando. 2014. "Making Sense of Culture." Annual Review of Sociology 40: $1-30$.

Pennycook, Gordon. 2018. "A Perspective on the Theoretical Foundation of Dual Process Models." Pp. 5-27 in Dual Process Theory 2.0, edited by Wim De Neys. New York: Routledge.

Pugh, Allison. 2013. "What Good Are Interviews for Thinking About Culture? Demystifying Interpretive Analysis." American Journal of Cultural Sociology 1(1): 42-68.

Ramvi, Ellen, Julian Manley, Lynn Froggett, Anne Liveng, Aase Lading, Wendy Hollway, and Birgitta Haga Gripsrud. 2018. "The Visual Matrix Method in a Study of Death and Dying: Methodological Reflections." Psychoanalysis, Culture \& Society 24(1): 31-52.

Reyna, Valerie F., Shahin Rahimi-Golkhandan, David M. N. Garavito, and Rebecca K. Helm. 2018. “The Fuzzy-Trace Dual Process Model.” Pp. 82-99 in Dual Process Theory 2.0, edited by Wim De Neys. New York: Routledge.

Schonwetter, Ronald S., Robert M. Walker, David R. Kramer, and Bruce E. Robinson. 1993. "Resuscitation Decision Making in the Elderly: The Value of Outcome Data." Journal of General Internal Medicine 8(6): 295-300.

Schucter, Stephen R., and Sidney Zisook. 2003. "The Course of Normal Grief." Pp. 23-43 in Handbook of Bereavement: Theory, Research, and Intervention, edited by Margaret S. Stroebe, Wolfgang Stroebe, and Robert O. Hansson. Cambridge: Cambridge University Press.

Seymour, Jane. 2003. "Technology and 'Natural Death': A Study of Older People." Zeitschrift für Gerontologie und Geriatrie 36(5): 339-346.

Silver, Daniel. 2011. "The Moodiness of Action.” Sociological Theory 29(3): 199-222.

Silverman, Phyllis R., and J. William Worden. 2003. "Children's Reactions to the Death of a Parent." Pp. 300-316 in Handbook of Bereavement: Theory, Research, and Intervention, edited by Margaret S. Stroebe, Wolfgang Stroebe, and Robert O. Hansson. Cambridge: Cambridge University Press.

Singer, Peter A., Douglas K. Martin, and Merrijoy Kelner. 1999. "Quality End-ofLife Care: Patients' Perspectives." The Journal of the American Medical Association 281(2): 163-168.

Solvberg, Lisa M. B., and Vegard Jarness. 2019. "Assessing Contradictions: Methodological Challenges When Mapping Symbolic Boundaries." Cultural Sociology. doi:10.1177/1749975518819907.

Stansbury, James, Marianne Mathewson-Chapman, and Kathryn E. Grant. 2003. "Gender Schema and Prostate Cancer: Veterans' Cultural Model of Masculinity." Medical Anthropology 22(2): 175-204.

Sun, Ron, Paul Slusarz, and Chris Terry. 2005. "The Interaction of the Explicit and the Implicit in Skill Learning: A Dual-Process Approach.” Psychological Review 112(1): 159-192. 
Swidler, Ann. 1986. "Culture in Action: Symbols and Strategies." American Sociological Review 51(2): 273-286.

Swidler, Ann. 2001. Talk of Love: How Culture Matters. Chicago, IL: University of Chicago Press.

Tedeschi, Richard G., Jane Shakespeare-Finch, Kanako Taku, and Lawrence G. Calhoun. 2018. Posttraumatic Growth: Theory, Research, and Applications. New York: Routledge.

Tedeschi, Richard G., and Lawrence G. Calhoun. 1996. "The Posttraumatic Growth Inventory: Measuring the Positive Legacy of Trauma." Journal of Posttraumatic Stress 9(3): 455-471.

Vaisey, Stephen. 2009. "Motivation and Justification: Toward a Dual-Process Theory of Culture in Action. American Journal of Sociology 114: 1675-1715.

Vaisey, Stephen. 2014. "Is Interviewing Compatible with the Dual-Process Model of Culture?" American Journal of Cultural Sociology 2(1): 150-158.

Vaisey, Stephen, and Omar Lizardo. 2010. "Can Cultural Worldviews Influence Network Composition?” Social Forces 88: 1595-1618.

Van Raalte, Judy L., Andrew Vincent, and Britton W. Brewer. 2016. "Self-Talk: Review and Sport-Specific Model.” Psychology of Sport and Exercise 22: 139-148.

Vandrevala, Tushna, Sarah E. Hampson, Tom Daly, Sara Arber, and Hilary Thomas. 2006. "Dilemmas in Decision-Making About Resuscitation - A Focus Group Study of Older People.” Social Science \& Medicine 62(7): 1579-1593.

Vaughan, Diane. 1996. The Challenger Launch Decision: Risky Technology, Culture and Deviance at NASA. Chicago, IL: University of Chicago Press.

Vila-Henninger, Luis Antonio. 2015. "Toward Defining the Causal Role of Consciousness: Using Models of Memory and Moral Judgment from Cognitive Neuroscience to Expand the Sociological Dual-Process Model." Journal for the Theory of Social Behaviour 45: 238-260.

Winchester, Daniel. 2016. "A Hunger for God: Embodied Metaphor as Cultural Cognition in Action." Social Forces 95(5): 85-606.

Winchester, Daniel, and Kyle Green. 2019. "Talking Yourself into It: How and When Accounts Shape Motivation for Action.” Sociological Theory 37(3): 257-281.

Wood, Michael Lee, Dustin S. Stoltz, Justin Van Ness, and Marshall A. Taylor. 2018. "Schemas and Frames." Sociological Theory 36(3): 244-261. 